\title{
THE PROMISE AND PERIL OF USING DISABILITY LAW AS A TOOL FOR SCHOOL REFORM
}

\author{
Claire Raj*
}

Abstract: Advocates have recently devised a radical litigation approach to force broad systemic changes in public schools using the most unlikely of tools: disability law. If they succeed, disability law stands to eclipse any other cause of action as the most effective means of school reform. This novel approach relies on groundbreaking research demonstrating a correlation between Adverse Childhood Experiences (ACEs) that children encounter outside school and the learning challenges they face in school. Focusing on this link, advocates claim that children from impoverished and crime-ridden neighborhoods, by virtue of where they live, have disabilities that entitle them to system-wide school remedies under federal law.

While this litigation exposes the depth of student need in high-poverty communities, the strategy is legally flawed and risks under-explored collateral consequences. Although advocates are correct that many of these children warrant individual remedies, using disability law to achieve system-wide educational reform is both unwise and unfeasible. First, such claims falsely assume that schools must identify all students who have any type of disability, when in fact schools' substantive duties are limited to those students whose disabilities require special education or related services to ensure meaningful access to education. Second, disability law mandates services that meet individual students' needs. Claims seeking schoolwide programmatic changes for all students are simply not legally required. Finally, classifying entire communities as disabled is over-inclusive and has the potential to stigmatize, albeit unfairly, all impoverished minority children as impaired.

This Article proposes a more nuanced litigation strategy and a broader legislative agenda. First, advocates should use schools' obligations to individual ACEs-impacted students to force schools to adopt more effective early identification processes. Schools should not assume all children have a disability, but identify those who do earlier. Second, federal and state legislation should provide targeted grants to schools that serve a high percentage of students impacted by ACEs. This approach would address unmet needs of students while guarding against over-inclusion.

\footnotetext{
* Assistant Professor, University of South Carolina School of Law. Thanks to the participants of the AALS Clinical Conference, Works in Progress section and in particular to David Moss who provided insightful feedback on an early draft. Thanks as well to my research assistant, Alex Hamrick, who diligently raced down rabbit holes in the name of research. Finally, thanks to Christopher Church who dropped the idea of "ecological fallacy" into my brain which helped crystalize some of the dangers lurking in a class action approach to reform.
} 


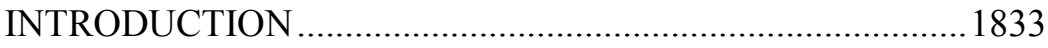

I. ADVERSE CHILDHOOD EXPERIENCES (ACES)

MEETS DISABILITY RIGHTS .....................................1841

A. The Science: Exploring the Impacts of ACEs ...........1841

1. ACEs Defined....................................................... 1841

2. ACEs and Child Development ..............................1843

3. ACEs and Chronically Impoverished Communities

B. The Laws: An Overview of Disability Rights

Laws

1. The Individuals with Disabilities Education Act 1847

2. Section 504 of the Rehabilitation Act and Title II of the Americans with Disabilities Act.... 1849

C. The Strategy: Combining Science and Disability Laws to Reform Sub-Standard Schools

II. TESTING THE THEORY: ACES AS DISABILITY .....1856

A. Eligibility under Section 504 and the ADA ..............1856

B. Eligibility Under the IDEA ………...........................1859

III. FLAWS IN THE LEGAL STRATEGY ............................1862

A. The Limits of Child Find..............................................1862

1. Child Find: The Obligation to the Community...1863

2. Child Find: The Obligation to the Individual .....1864

3. Child Find: The Implications for ACEs................1867

B. The Limits of Free Appropriate Public Education

(FAPE) ............................................................. 1870

1. Clarifying Section 504's FAPE Obligation .........1870

2. The Impossibility of Class-based Remedies for Programmatic Change

C. Additional Legal Hurdles ............................................ 1876

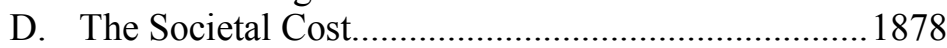

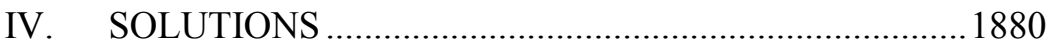

A. Turning Individual Rights into Systemic Solutions .1881

B. Creating Federal Grants to Address System-Wide Supports............................................................... 1886

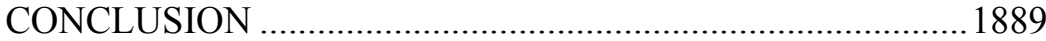




\section{INTRODUCTION}

America's public schools are overtasked, under-resourced, and increasingly responsible for educating large communities of students with unmet physical, medical, and psychological needs. ${ }^{1}$ While federal programs exist to address some of these concerns, thus far, these programs have proven insufficient to fully remediate the considerable challenges facing public schools. ${ }^{2}$ Advocates are now attempting a creative and radical litigation strategy to force broad-based changes in public schools. And, they are using the most unlikely of tools - disability rights laws. ${ }^{3}$ If they succeed, disability rights laws stand to eclipse any other cause of action as a means of school reform. ${ }^{4}$ But before diving over this precipice,

1. Ulrich Boser, Perpetual Baffour \& Steph Vela, Ctr. for Am. Progress, A Look at THE EDUCATION CRISIS: TESTS, STANDARDS, AND THE FUTURE OF AMERICAN EDUCATION 5 (Jan. 2016), https://cdn.americanprogress.org/wp-content/uploads/2016/01/21075127/TUDAreport.pdf [http://perma.cc/QPS2-8PKH] ("While there has been substantial progress over the past decadeparticularly in cities and states that have embraced standards-based reform - the nation still faces a pressing education crisis, particularly when it comes to students of color and students from lowincome backgrounds."); see, e.g., S. EDUC. Found., A NEW MAJORITY: LOW INCOME STUDENTS Now A MAJORITY IN THE NATION's Public Schools (2015), https://www.southerneducation.org/Our-Strategies/Research-and-Publications/New-MajorityDiverse-Majority-Report-Series/A-New-Majority-2015-Update-Low-Income-Students-Now [https://perma.cc/6DAT-5ZYL].

2. In fact, current federal funds constitute less than $10 \%$ of overall education spending. STEPHEN Q. CORNMAN ET AL., NAT'L CTR. FOR EDUC., U.S. DEP'T OF EDUC., REVENUES AND EXPENDITURES FOR PUBlic ElEMENTARY AND SECONDARY EdUCATION: SCHOOL YEAR 2014-15 (Fiscal YeAR 2015) 4-5 (2018), https://nces.ed.gov/pubs2018/2018301.pdf [https://perma.cc/UBF6-2WH7]; see generally BRUCE D. BAKER ET AL., EDUC. LAW CTR., IS SCHOOL FUNDING FAIR? A NATIONAL REPORT CARD (2010), https://drive.google.com/file/d/0BxtYmwryVI00U2doWDhYUD N6Ylk/view [https://perma.cc/BF2T-HFSE] (noting that funding levels nationally are well below levels necessary for low-income students to achieve above-average outcomes); Joel Klein, The Failure of American Schools, ATLANTIC (June 2011), https:/www.theatlantic.com/magazine/archiv e/2011/06/the-failure-of-american-schools/308497/ [https://perma.cc/8CNA-PLRX] ("[T]he gains we have made in improving our schools are negligible — even though we have doubled our spending (in inflation-adjusted dollars) on K-12 public education.").

3. Stephen C. v. Bureau of Indian Educ., No. CV-17-08004-PCT-SPL, 2018 WL 1871457 (D. Ariz. Mar. 29, 2018); P.P. v. Compton Unified Sch. Dist., 135 F. Supp. 3d 1098 (C.D. Cal. 2015).

4. Currently, no general federal constitution cause of action for school reform exists because the Supreme Court rejected education as a fundamental right. San Antonio Indep. Sch. Dist. v. Rodriguez, 411 U.S. 1, 35 (1973) ("Education, of course, is not among the rights afforded explicit protection under our Federal Constitution. Nor do we find any basis for saying it is implicitly so protected."). Other federal claims with the potential for systemic relief, including Title VI of the Civil Rights Act of 1964, 42 U.S.C. § 2000d-2000d-7 (2012), and Title IX of the Education Amendments of 1972, 20 U.S.C. $\$ 1681-88$ (2012), require plaintiffs to prove intentional discrimination in order to win reliefa burden few have managed to overcome. Derek W. Black, The Mysteriously Reappearing Cause of Action: The Court's Expanded Concept of Intentional Gender and Race Discrimination in Federally Funded Programs, 67 MD. L. REV. 358 (2008). Finally, while systemic claims for reform are generally available under education clauses in state constitutions, those rights are perpetually difficult to enforce. William S. Koski, Of Fuzzy Standards and Institutional Constraints: A Re-Examination of the Jurisprudential History of Educational Finance Reform Litigation, 43 SANTA ClaRA L. REV. 1185 (2003). 
two crucial questions should be answered: (1) can advocates use disability rights laws as agents of systemic educational reform?; and (2) should they?

The effort to leverage disability rights laws for school reform is rooted in groundbreaking research on Adverse Childhood Experiences (ACEs). ${ }^{5}$ ACEs refer to specific categories of adversity - physical and emotional abuse, neglect, and household dysfunction - that are strongly correlated with poor long-term health outcomes. ${ }^{6}$ While ACEs are quite common and transcend socio-economic status, children raised in communities of poverty are more likely to be exposed to multiple and persistent ACEs, including food insecurity, lack of stable housing, and community violence. ${ }^{7}$ New research exploring ACEs links these experiences to wideranging challenges that impede a student's ability to learn, including difficulty regulating emotions, outsized anxiety or fear, and delayed executive functioning skills. ${ }^{8}$

Public education advocates are creatively weaving this research into legal claims for systemic educational reform. Relying on ACEs research, they argue that children from impoverished and crime-ridden neighborhoods are individuals with disabilities due to the impacts of chronic poverty and community violence. ${ }^{9}$ As such, they argue these students should be entitled to supports and accommodations that ensure equal access to education. ${ }^{10}$ More specifically, they argue that disability rights laws require public schools in these communities to make systemic programmatic changes to address the disability-related needs of these

5. See, e.g., Vincent J. Felitti et al., Relationship of Childhood Abuse and Household Dysfunction to Many of the Leading Causes of Death in Adults: The Adverse Childhood Experiences (ACE) Study, 14 AM. J. PREVENTIVE MED. 245 (1998).

6. $I d$.

7. Child Trends, Adverse Childhood Experiences (Mar. 7, 2019), [hereinafter Child TRENDS] https://www.childtrends.org/indicators/adverse-experiences [https://perma.cc/Y7QBJW3E] (analyzing data from the National Survey of Children's Health 2011-2016, and concluding that "[p] ]oor children and near-poor children are more than twice as likely than [sic] their more affluent peers to have had three of more other adverse experiences"); see also Gary W. Evans \& Pilyoung Kim, Childhood Poverty, Chronic Stress, Self-Regulation, and Coping, 7 CHILD DEV. PERSP. 43-48 (2013) (discussing how children growing up in poverty are more likely to "experience a greater array of physical and psychosocial stressors," including family conflict and turmoil and exposure to violence).

8. Ron Hertel \& Mona M. Johnson, How the Traumatic Experiences of Students Manifest in School Settings, in Supporting and Educating Traumatized Students: A Guide For School-Based Professionals 23-47 (Eric Rossen \& Robert Hull eds., 2013).

9. See generally Complaint for Declaratory and Injunctive Relief, Stephen C. v. Bureau of Indian Educ., (D. Ariz. Jan. 12, 2017) (No. 3:17-cv-08004-SPL) [hereinafter Stephen C. Complaint]; Class Action Complaint, P.P. v. Compton Unified School Dist., 135 F. Supp. 3d 1098 (C.D. Cal May, 18, 2015) (No. LA CV15 3726 MWF (PLAX)) [hereinafter P.P. Complaint].

10. Stephen C. Complaint, supra note 9, at 12; P.P. Complaint, supra note 9, at 72. 
students. ${ }^{11}$ These include changes to curriculum (teaching socialemotional learning skills), discipline (developing non-punitive restorative justice practices), and mental health support (offering access to schoolbased counseling). ${ }^{12}$

While these specific programmatic reforms may be both effective and grounded in evidence-based practices, it is far from clear that disability law requires these changes. Moreover, expanding disability categories to include entire communities of children creates the potential for other societal harms. In other words, disability rights statutes may not be the correct salve for these particular wounds.

No court has yet determined whether exposure to ACEs, or the likelihood of such exposure, qualifies as a bona fide disability under any of the disability rights statutes: the Individuals with Disabilities Education Act (IDEA), Section 504 of the Rehabilitation Act of 1973 (Section 504), or Title II of the Americans with Disabilities Act (ADA). ${ }^{13}$ At the core of each law is the right to supports-special education, accommodations, and other related services - when necessary to ensure that children with disabilities have access to the same curricula as their non-disabled peers. ${ }^{14}$ The trouble with the new litigation strategy is that while children impacted by ACEs could theoretically access protections under all three laws, their ability to do so will solely depend on individual experience with ACEs and resulting needs. ${ }^{15}$

Demonstrating a class claim based on exposure to ACEs is precarious at best because of the individualized nature of impacted children's experiences and needs. ${ }^{16}$ First, all three laws situate both students' rights and schools' obligations in the context of an individual child, not groups of children. ${ }^{17}$ The IDEA, for instance, restricts eligibility to thirteen categories of disability and requires a child to demonstrate that the disability adversely affects his or her educational performance and results in a need for special education services. ${ }^{18}$ While a student impacted by ACEs could potentially fit into one of the IDEA's disability categories,

11. See, e.g., Stephen C. Complaint, supra note 9, ๆ甲 3-13; P.P. Complaint, supra note 9, ๆ 4; 6171, 192-223.

12. P.P. Complaint, supra note 9 , at 62-64.

13. Individuals with Disabilities Education Act (IDEA), 20 U.S.C. $\S \S 1400-1482$ (2018); Rehabilitation Act of $1973 \S 504,29$ U.S.C. $§ 794$; Americans with Disabilities Act (ADA), 42 U.S.C. $\S \S 12101-12213$.

14. 20 U.S.C. $§ 1400(d) ; 29$ U.S.C. § 794(a); 42 U.S.C. $\$ 12132$.

15. See infra section II.B.

16. See infra section II.B.

17. 34 C.F.R. $§ 104.33$ (2019) (Free Appropriate Public Education (FAPE)); id. $§ 300.320$ (defining the Individualized Education Program (IEP)).

18. 20 U.S.C. $§ 1401(3)$; 34 C.F.R. $\S 300.8$ (defining children’s disabilities) 
many students suffering from the effects of ACEs will likely need mental health supports, but not necessarily special education services. ${ }^{19}$ Without a need for specialized instruction, the IDEA becomes inaccessible to students impacted by ACEs. Section 504 and the ADA present similar, albeit distinct, problems.

Section 504 and the ADA define disability in much broader terms. ${ }^{20}$ Those broader terms could make individual students impacted by ACEs eligible for legal protections. Yet, leveraging these laws for systemic relief is tenuous. The most a class can claim is probable exposure to ACEs. ${ }^{21}$ But Section 504 and the ADA-just like the IDEA-require individualized eligibility determinations before schools are obligated to provide special education or other supports. ${ }^{22}$ Crucially, knowledge that a child lives in chronic poverty and has exposure to ACEs does not, alone, trigger a right to special education services or accommodations under either law. ${ }^{23}$

Second, these class action claims make false assumptions about schools' affirmative duties to identify students suspected of having disabilities. While disability law requires schools to affirmatively seek out children suspected of having a disability and in need of special education - known as "child find" obligations - schools are simply not obligated to identify all children with disabilities in all cases. ${ }^{24}$ Rather, child find obligations are limited to identifying a subset of students with disabilities - those whose disabilities impact their education and require special education, accommodations, or other related services. ${ }^{25}$ In other words, schools have no obligation to seek out students with disabilities for census purposes alone - to simply document how many exist. ${ }^{26}$ This

19. Ctr. on Developing Child, Harvard Univ., From Best Practices to Breakthrough ImPaCts: A SCIENCE-BASEd APPROACH to Building A More Promising Future for Young CHILDREN AND FAMILIES (2016), https://46y5eh11 fhgw3ve3ytpwxt9r-wpengine.netdna-ssl.com/wpcontent/uploads/2016/05/From_Best_Practices_to_Breakthrough_Impacts-4.pdf [https://perma.cc/AR9L-KSP8].

20. 29 U.S.C. § 794(a); 42 U.S.C. § 12131(2).

21. See infra Part III.

22. 34 C.F.R. $\$ 104.35$ (discussing evaluation and placement); see also Protecting Students with Disabilities: Frequently Asked Questions About Section 504 and the Education of Children with Disabilities, U.S. DEP'T EDUC.: OFFICE C.R.., https://www2.ed.gov/about/offices/list/ocr/504faq.html [https://perma.cc/V5RD-2ZUD] [hereinafter U.S. DEP'T EDUC., FAQS] (FAQ\# 34).

23. 34 C.F.R. $\S 104.35$. Instead, disability rights laws require individualized assessments to determine whether a disability exists and what, if any, special education or related services are required to ensure meaningful access to education.

24. See infra section III.A.

25. See infra section III.A.2.

26. See infra section III.A.2. 
presents a problem for a plaintiff's ACEs theory. ${ }^{27}$ Not all children exposed to trauma will experience the same effects. ${ }^{28}$ A school can be aware of the potential impacts of ACEs on child development, learning, and behavior, but that awareness does not necessarily trigger an obligation to begin the eligibility process in all cases. And it certainly does notwithout evaluation-immediately trigger the obligation to provide accommodations, special education, or related services. ${ }^{29}$

Third, these cases conflate an obligation to identify students with disabilities with the obligation to provide affirmative education services and supports. The duty to identify students, as contained in child find, is universal; it applies to all students suspected of having disabilities that require special education or related services. ${ }^{30}$ But, the duty to provide affirmative services to ensure a Free Appropriate Public Education (FAPE) is an individual right. ${ }^{31}$ FAPE is rooted in an individual child's right to an educational program designed to meet their needs as adequately as their non-disabled peers. ${ }^{32}$

Class claims demanding system-wide changes in educational services have the power to effectively alter education for all students. ${ }^{33}$ By definition, systemic reforms that change the delivery of education for all children are not tied to an individual student's needs, but rather are driven by the group's collective needs. ${ }^{34}$ While the group may, in fact, require

27. Stephen C. Complaint, supra note 9, ๆๆ 306-18; P.P. Complaint, supra note 9, ๆף 201-07 (discussing plaintiffs' theory that school districts are liable under Section 504 for their failure to identify students experiencing ACEs as students with disabilities).

28. About ACEs, CTRS. FOR DiseAsE CONTROL \& Prevention, https://www.cdc.gov/violenceprevention/childabuseandneglect/acestudy/aboutace.html

[https://perma.cc/WMA5-PV2V] ("The presence of ACEs does not mean that a child will experience poor outcomes. However, children's positive experiences or protective factors can prevent children from experiencing adversity and can protect against many of the negative health and life outcomes even after adversity has occurred.").

29. See infra section III.A.3.

30. Free Appropriate Public Education (FAPE), 34 C.F.R. $\S \S 104.32(a), 104.35$ (a) (2019).

31. Id. $\S 104.33$.

32. Id. $\S 104.33$ (b)-(c). In order to satisfy Section 504's FAPE requirement, a school must comply with evaluation and placement requirements, afford procedural safeguards, and inform students' parents or guardians of those safeguards. Id. $\S 104.35$ (a) (evaluation and placement); Id. $\S 104.36$ (procedural safeguards).

33. Likely the most famous class-based claim in the context of education reform is Brown v. Board of Education, 347 U.S. 483 (1954) (holding that separate but equal educational facilities for racial minorities is inherently unequal, violating the Equal Protection Clause of the Fourteenth Amendment).

34. Systemic Reform, Glossary EDUC. REFORM (Aug. 29, 2013), https://www.edglossary.org/systemic-reform/ [https://perma.cc/WT8Z-X2GP] ("[T] he concept of systemic reform may be used in reference to (1) reforms that impact multiple levels of the education system, such as elementary, middle, and high school programs; (2) reforms that aspire to make changes throughout a defined system, such as district-wide or statewide reforms; (3) reforms that are intended to influence, in minor or significant ways, every student and staff member in school or 
and benefit from these curricular changes, the FAPE standard - and thus disability rights law - does not compel them.

Relatedly, by demanding system-wide relief, these lawsuits stretch the purpose of disability law, and by doing so, risk over-inclusion. Although the IDEA, Section 504, and the ADA have brought about sweeping changes for students with disabilities, over time, none of these laws were enacted to facilitate school-wide curricular remedies. ${ }^{35}$ Moreover, schoolwide remedies would capture both students who need these additional supports as well as students who may not. While this may be an efficient way to address the broader impacts of ACEs, the law only requires remedies targeted at individual student needs. ${ }^{36}$

Finally, broadening disability eligibility to include mere exposure to ACEs can have the unintended consequence of unfairly stigmatizing impoverished minority children as impaired. ${ }^{37}$ While ACEs cut across socio-economic classes, certain individuals are at higher risk for exposure to ACEs. ${ }^{38}$ Children at or near the poverty level are more than twice as likely as affluent children to experience a statistically significant number of ACEs. ${ }^{39}$ Because children in neighborhoods of concentrated poverty and violence have greater obvious exposure to ACEs, entire neighborhoods of children could be classified as disabled. ${ }^{40}$ Of course, students with disabilities do not deserve the stigma sometimes associated with disability. And while society has come a long way in its general understanding and respect for persons with disabilities, barriers to

system; or (4) reforms that may vary widely in design and purpose, but that nevertheless reflect a consistent educational philosophy or that are aimed at achieving common objectives.").

35. 20 U.S.C. $§ 1400$ (2012) (short title; findings; purposes); see also 29 U.S.C. $§ 794$ (2012) (nondiscrimination under federal grants and programs); Honig v. Doe, 484 U.S. 305, 309-13 (1988); Mark C. Weber, A New Look at Section 504 and the ADA in Special Education Cases, 16 TEX. J. ON C.L. \& C.R. 1 (2010); U.S. DEP'T EDUC., FAQS, supra note 22 ("Section 504 is a federal law designed to protect the rights of individuals with disabilities in programs and activities that receive Federal financial assistance from the U.S. Department of Education.").

36. See infra section III.B.

37. See infra section III.D.

38. Melissa T. Merrick et al., Prevalence of Adverse Childhood Experiences from 2011-2014 Behavioral Risk Factor Surveillance System in 23 States, 172 JAMA PEDIATRICS 1038, 1038 (2018) (finding that "participants who identified as black, Hispanic, or multiracial, those with less than a high school education, those with annual income less than $\$ 15,000$, those who were unemployed or unable to work, and those identifying as gay/lesbian or bisexual reported significantly higher exposure to [ACEs] than comparison groups").

39. CHILD TRENDS, supra note 7 ("Poor children and near-poor children are more than twice as likely than their more affluent peers to have had three or more other adverse experiences.").

40. For example, the plaintiffs in the P.P. case alleged that all children in Compton should be considered individuals with disabilities under Section 504. P.P. Complaint, supra note 9, at 58. 
acceptance still remain. ${ }^{41}$ Certainly, ensuring students receive the supports they need to succeed is beyond reproach. But assuming all children, by virtue of growing up in a certain community, are in need of special education or accommodations is stigmatizing and can have long-term negative consequences on how these students view themselves and are viewed by others. ${ }^{42}$

The foregoing critiques are hard ones to lodge. Children from struggling communities plagued by drug epidemics, marred by violence, and devoid of economic development are, undoubtedly, negatively impacted by those environments. ${ }^{43}$ These children can struggle to manage stress and regulate emotions, thereby limiting their chances of educational success. ${ }^{44}$ Advocates' new claims shine a much-needed spotlight on the breadth and immediacy of this problem. Their efforts underscore the fact that community wide challenges require large-scale fixes. This Article echoes all these concerns, even if it raises questions about whether and how disability law provides a remedy. The solution, however, is not to fit a square peg into a round hole.

The solution is to fill the gap in existing laws and remedies that this Article's critique reveals. First, rather than leveraging disability rights laws for sweeping programmatic changes, advocates should leverage the laws' child find mandate in individual cases where students are clearly evidencing learning or behavioral challenges. Methodically bringing a series of child find claims would pressure schools to enhance their screening tools. Enhanced screening tools would, in turn, improve early identification of ACEs-impacted students. ${ }^{45}$ Advocates could demand comprehensive evaluations for these individual students followed by individualized education plans aimed at remediating the effects of ACEs. In short, rather than assuming all children have a disability, this strategy forces schools to identify those who do earlier. Moreover, if aggregate results reveal that a critical mass of individual students could benefit from the same supports, such as mental health counseling and social emotional skills training, a school could elect to offer such changes school-wide. This is the very remedy the current lawsuits seek. But this choice would be based on the

41. Brian East, Struggling to Fulfill Its Promise: The ADA at 15, 68 TEX. B.J. 614, 615 (2005) (arguing that judicial opposition exists toward the ADA preventing disabled individuals from reaping its intended benefits).

42. See infra section III.D.

43. Evans \& Kim, supra note 7, at 44 (discussing how children growing up in poverty are more likely to "experience a greater array of physical and psychosocial stressors" including family conflict and turmoil and exposure to violence).

44. Nadine J. Burke et al., The Impact of Adverse Childhood Experiences on an Urban Pediatric Population, 35 ChILd ABUSE \& Neglect 408 (2011).

45. See infra section IV.G. 
school's response to individualized data gathered on their student population, not on broad assumptions based on community characteristics.

Second, federal and state legislators should create targeted grants that direct funding to schools serving large populations of students impacted by ACEs. ${ }^{46}$ School districts could apply for funding upon a showing that a threshold percentage of their student population was exposed to a statistically significant number of ACEs. ${ }^{47}$ This funding could be used to implement trauma-informed training for teachers and school officials, mental health counseling for students, and other evidence-based interventions that have proven effective in addressing the impacts of ACEs. The availability of these grants would incentivize school districts to be proactive in identifying and serving students impacted by ACEs. ${ }^{48}$ They would also facilitate a grassroots approach, encouraging communities to identify their particular needs and the resources that would best meet those needs.

Critics may argue that children facing the immediate challenges of high crime and poverty cannot wait for Congress to act or for schools to choose to address their needs. And they are right - these children need relief now. But disability laws can pressure school districts to address at least some of their educational needs without distorting the overall legal framework. Stretching the laws beyond their bounds is just as likely to undermine support and enforcement of the laws as it is to secure the remedies plaintiffs seek. The IDEA, for instance, already provides far fewer resources than schools need and is routinely charged as being overly burdensome. ${ }^{49}$ The better approach is to continue to fight for ACEsimpacted children through provisions that grant established individualized remedies for such students, such as comprehensive evaluations to address individualized needs, and pursue congressional action for systemic remedies that are not currently available. Proceeding with this more measured approach will help guard against the dangers of over-inclusion.

\footnotetext{
46. See infra section IV.H.

47. Felitti et al., supra note 5 (demonstrating an increased chance of negative health outcomes when four or more ACEs are identified).

48. While over-identification of children with disabilities is always a concern, this solution mitigates against that problem because funding flows from exposure to a statistically significant number of risk factors. It is not tied to disability category or eligibility as an "individual with a disability." See infra section IV.B.

49. See generally Miriam Kurtzig Freedman, Special Education: Its Ethical Dilemmas, Entitlement Status, and Suggested Systemic Reform, 79 U. CHI. L. REV. 1 (2012) (arguing that the IDEA as written has outlived its purpose and instead created many unintended consequences including an increase in children eligible under the IDEA and thus an increased cost to educating these students, and stressful procedural demands that take teachers out of classrooms and away from teaching).
} 


\section{ADVERSE CHILDHOOD EXPERIENCES (ACES) MEET DISABILITY RIGHTS}

\section{A. The Science: Exploring the Impacts of ACEs}

In 1998, a groundbreaking study from the Centers for Disease Control and Prevention (CDC) and Kaiser Permanente shifted the way the scientific community conceptualized adult physical and mental health by identifying a correlation between ACEs and poor adult health outcomes. ${ }^{50}$ Since then several studies have further explored the impacts of adverse childhood experiences on adult health outcomes, as well as child physical and mental health. ${ }^{51}$ An expanding body of research now supports the theory that ACEs can disrupt healthy brain development with significant implications for learning, behavior, and health. ${ }^{52}$

\section{ACEs Defined}

The original ACEs study consisted of nine categories: emotional abuse, physical abuse, sexual abuse, emotional and physical neglect, household substance abuse, household mental illness, parental separation or divorce, household domestic violence, and incarcerated household member. ${ }^{53}$ Additional adverse factors have been added to the original study, including death of a parent, community violence, and poverty. ${ }^{54}$ While some stress in life is normal and can even promote healthy development, the type of stress that results when a child experiences ACEs may become destructive when there is "strong, frequent, or prolonged activation of the body's stress response systems in the absence of the buffering protection

50. See generally Felitti et al., supra note 5.

51. Marilyn Metzler et al., Adverse Childhood Experiences and Life Opportunities: Shifting the Narrative, 72 CHILD. \& YouTH SERVS. REV. 141, 147 (2016); see also E. Jane Costello et al., The Prevalence of Potentially Traumatic Events in Childhood and Adolescence, 15 J. TRAUMATIC STRESS 99, 107 (2002); Araceli Gonzalez et al., Trauma Exposure in Elementary School Children: Description of Screening Procedures, Level of Exposure, and Posttraumatic Stress Symptoms, 8 SCH. Mental HeAlth 77, 83 (2016); Johanna K.P. Greeson et al., Traumatic Childhood Experiences in the 21st Century: Broadening and Building on the ACE Studies with Data from the National Child Traumatic Stress Network, 29 J. INTERPERSONAL VIOLENCE 536, 548-50 (2014); Violence Prevention: Risk and Protective Factors, Ctrs. Disease Control \& Prevention (Feb. 27, 2019), http://www.cdc.gov/ViolencePrevention/youthviolence/riskprotectivefactors.html [https://perma.cc/EC3J-LML2].

52. Laura J. Hickman et al., How Much Does "How Much" Matter?: Assessing the Relationship Between Children's Lifetime Exposure to Violence and Trauma Symptoms, Behavior Problems, and Parenting Stress, 28 J. InTERPERSONAL VIOLENCE 1338, 1341, 1355-56 (2012); Jack P. Shonkoff et al., The Lifelong Effects of Early Childhood Adversity and Toxic Stress, 129 PEDIATRICS e232, e237 (2012), http://pediatrics.aappublications.org/content/pediatrics/129/1/e232.full.pdf [https://perma.cc/GQ8X-AV3H].

53. Felitti et al., supra note 5, at 248.

54. Metzler et al., supra note 51, at 142. 
of a supportive, adult relationship." 55 Scientists categorize this type of stress as "toxic" because it can lead to long-term impairment and can actually disrupt the development of brain architecture and other organ systems. ${ }^{56}$ Studies have demonstrated a "dose-response" relationship between a person's number of ACEs and resulting psychological and physical conditions ${ }^{57}$ The original ACEs study evidenced that adults who identified more than four ACE categories were more likely to suffer from various chronic diseases than adults with zero ACEs. ${ }^{58}$

The fact that a child has experienced one of the categories of ACEs does not automatically indicate that the child will experience long-term negative impacts on health or development. ${ }^{59}$ Children, like adults, vary in their capacity to develop resiliency. Some will surely develop internal and external resources to manage these negative experiences. ${ }^{60}$ ACEs become problematic when a child lacks the tools to overcome them. Moreover, as the following discussion illuminates, the more ACEs children encounter, the more likely they are to experience toxic stress and the corresponding negative impacts on health and development.

Before moving on, it is helpful to clarify terminology used to describe the impact of exposure to multiple or persistent ACEs. The term "toxic stress" is used to describe the point at which ACEs begin to negatively impact physical and emotional health. ${ }^{61}$ The term "complex trauma" is also generally used to describe exposure to multiple traumatic events and

55. Shonkoff et al., supra note 52, at e236.

56. Id. "[T] he National Scientific Council on the Developing Child coined the term 'toxic stress' to describe extensive, scientific knowledge about the effects of excessive activation of stress response systems on a child's developing brain, as well as the immune system, metabolic regulatory systems, and cardiovascular system." ACEs and Toxic Stress: Frequently Asked Questions, CTR. ON THE DEVELOPING CHILD: HARV. U., https://developingchild.harvard.edu/resources/aces-and-toxic-stressfrequently-asked-questions/\#ACEs [https://perma.cc/HJD9-FE6C].

57. Felitti et al., supra note 5, at 250.

58. Id. Subsequent studies have shown that adults endorsing more than 4 ACEs are 2.6 times as likely to have Chronic Obstructive Pulmonary Disease (COPD), hepatitis (2.4 times as likely), sexually transmitted infections (2.5) and injection drug use (4.6). Id. at 245.

59. Violence Prevention, CTRS. DiseAse CONTROL \& Prevention, https://www.cdc.gov/violenceprevention/childabuseandneglect/acestudy/aboutace.html [https://perma.cc/B3UV-EW6J] ("The presence of ACEs does not mean that a child will experience poor outcomes. However, children's positive experiences or protective factors can prevent children from experiencing adversity and can protect against many of the negative health and life outcomes even after adversity has occurred.").

60. Id.; see also Cathryn Delude, Scars That Don't Fade, Рroto (Dec. 23, 2015), $\mathrm{http}: / /$ protomag.com/articles/scars-that-dont-fade [https://perma.cc/47RP-HS2M] (discussing how researchers are trying to understand "the mechanisms that enable some children to handle stress even when it becomes chronic").

61. Shonkoff et al., supra note 52, at e236. 
the resulting symptoms, which can be both physical and psychological. ${ }^{62}$ Complex trauma is sometimes used to describe exposure of four or more ACEs. ${ }^{63}$ This Article will use both "complex trauma" and "toxic stress" to mean exposure to multiple or persistent ACEs that has resulted in negative physical or psychological symptoms.

\section{ACEs and Child Development}

Numerous studies have demonstrated the impacts toxic stress can have on both physical and mental health for children. ${ }^{64}$ Beginning as early as the prenatal period, fetal exposure to maternal stress can influence later stress responsiveness. ${ }^{65}$ Persistently elevated levels of stress hormones can actually change the physical development of the brain which can impact several important physiological and cognitive functions. ${ }^{66}$ For instance, exposure to stressful experiences has been shown to influence attention, memory, learning, and executive functioning (the umbrella term to describe skills needed for self-regulation and mental control). ${ }^{67}$ Consequently, when a child grows up under constant or extreme stress, the body's stress-response systems may not develop normally.

A child experiencing multiple or persistent ACEs may have an altered baseline state of cognitive arousal. ${ }^{68}$ Thus, even when there is no external threat, the child is physiologically experiencing a state of fight or flight. ${ }^{69}$ When this child encounters even ordinary levels of stress, the child may automatically respond as if under extreme stress. ${ }^{70}$ For example, the child may experience rapid breathing or heart pounding, or may completely

62. Alexandra Cook et al., Nat'l Child Traumatic Stress Network Complex Trauma TASK ForCe, COMPlex Trauma In CHILdREN AND AdOLESCENTS 5 (2003).

63. David Dante Troutt, Trapped in Tragedies: Childhood Trauma, Spatial Inequality, and Law, 101 Marq. L. ReV. 601, 610 (2018); Effects, NAT'L Child Traumatic STRess Network [hereinafter Effects], https://www.nctsn.org/what-is-child-trauma/trauma-types/complextrauma/effects [https://perma.cc/BUY9-JGLA].

64. Gonzalez et al., supra note 51, at 83; Metzler et al., supra note 51, at 141-42 (citing to several studies within this paper); Bruce D. Perry \& Ronnie Pollard, Homeostasis, Stress, Trauma, and Adaptation: A Neurodevelopmental View of Childhood Trauma, 7 CHILD \& AdOLESCENT PSYCHIATRIC CliniCs N. AM. 33, 33-51 (1998).

65. See Shonkoff et al., supra note 52.

66. Id. at $\mathrm{e} 236$.

67. Id.

68. Perry \& Pollard, supra note 64, at 33-51 ("Simply stated, the child is in a persisting fear 'state.' ... the child's new basal homeostatic or equilibrium emotional state is a state of anxiety."); see also Delude, supra note 60 (discussing how "stress can become a chronic irritant" when the stressresponse system is repeatedly activated or fails to turn off).

69. Perry \& Pollard, supra note 64 , at 33-51.

70. Id. at 33-51 ("Everyday stresses that previously may not have elicited any response are now able to elicit an exaggerated reactivity in children who are hyperreactive and overly sensitive."). 
shut down. ${ }^{71}$ These responses are out of proportion to the level of stress encountered and can be perceived as “'overreacting,' or as unresponsive or detached." 72

The adaptive responses that help the child survive and cope in a chaotic and unpredictable home environment often put the child at a disadvantage in the educational setting. When a stressor arises - for example an argument with a peer or demanding school task - an ACEs-impacted child can escalate to a state of fear very quickly. As one researcher aptly described, "[a] child with a brain adapted for an environment of chaos, unpredictability, threat, and distress is ill-suited to the modern classroom or playground." 73 Thus, it will come as no surprise to learn that children coping with toxic stress have lower academic achievement, higher instances of behavioral problems, and are more likely to drop out of school altogether. ${ }^{74}$

Quite obviously, such outsized reactions to stress can inhibit a child's ability to successfully engage in school and navigate relationships with both teachers and peers. Children impacted by toxic stress are more likely to experience both academic failure and behavioral challenges in school. One study found that children who have experienced three or more ACEs faced the following consequences: they were four times more likely to experience academic failure, five times more likely to have serious attendance problems, and six times more likely to incur serious school behavior problems. ${ }^{75}$ As a result of the growing influence of ACEs research, many schools have begun to turn their attention towards adopting trauma-informed practices. ${ }^{76}$ Schools are beginning to realize that a majority of their student populations have encountered at least one

71. Id. (discussing the effects of repeated exposure to childhood trauma including: hyperactivity, anxiety, behavioral impulsivity, rapid heart rate, and "freezing").

72. Effects, supra note 63.

73. Bruce D. Perry, Maltreatment and the Developing Child: How Early Childhood Experience Shapes Child and Culture, CTR. ChILD. \& FAM. JuST. SYS. 2-3 (Sept. 23, 2004), http://www.lfcc.on.ca/mccain/perry.pdf [https://perma.cc/XB4N-BDQS] ("Compared to their peers, therefore, traumatized children may have less capacity to tolerate the normal demands and stresses of school, home, and social life.").

74. Hertel \& Johnson, supra note 8; AM. Pub. HeAlth Ass'N, Chronic Stress AND the RisK of High SCHOOL DROPOUT, 3-5 (2018), https://www.apha.org/-/media/files/pdf/sbhc/chronic_stress. ashx?la=en\&hash=F5FB7AF535D2CDA4CBC81236DBCE6580B53607E4 [https://perma.cc/PSP9MVBE]; Christopher M. Layne et al., Cumulative Trauma Exposure and High Risk Behavior in Adolescence: Findings from the National Child Traumatic Stress Network Core Data Set, 6 PSYCHOL. TRAUMA: THEORY, RES. PRAC. POL'y S40, S42, S45 (2014).

75. Christopher Blodgett, No School Alone: How Community Risks and Assets CONTRIBUTE TO SCHOOL AND YOUTH SUCCESS 25 (2015), https://traumasensitiveschools.org/wpcontent/uploads/2015/11/no_school_alone-Washington-State.pdf [https://perma.cc/M7H8-LZXJ].

76. 6 Ways to Become a Trauma-Informed School, NAT'L RESILIENCE INST. (May 17, 2017), https://nationalresilienceinstitute.org/2017/05/6-ways-become-trauma-informed-school/ [https://perma.cc/8GR3-22H5]. 
ACE. ${ }^{77}$ Further, as the following section describes, public schools comprised of a majority of students from impoverished communities may find much higher incidences of students impacted by toxic stress.

\section{ACEs and Chronically Impoverished Communities}

ACEs occur regularly with children across race, socio-economic class, and geographic regions, but children living in poverty are at higher risk for more ACEs. ${ }^{78}$ The more ACEs a child experiences, the more likely they are to have negative physical or psychological symptoms. ${ }^{79}$ Results of nationally collected data demonstrate that "poor children . . . are more than twice as likely than their more affluent peers to have had three or more adverse experiences." ${ }^{~}{ }^{\circ}$ Just as with adults, children experiencing multiple ACEs evidence an increased risk for poor outcomes. ${ }^{81}$ Children with two or more ACEs were nearly three times more likely to repeat a grade in school, compared to children without any ACEs. ${ }^{82}$ Children with four or more ACEs were significantly more likely to have learning or behavior problems than children reporting zero ACEs. ${ }^{83}$

Research clearly demonstrates that while ACEs are present in children nationwide, children in poverty are disproportionately exposed to more trauma-inducing events. ${ }^{84}$ Moreover, studies indicate a correlation between children raised in communities of chronic poverty and depressed cognitive

77. Responding to Trauma in K-12 Schools, NAT'L CTR. ON SAFE SUPPORTIVE LEARNING ENV'TS, https://safesupportivelearning.ed.gov/responding-trauma-k-12-schools [https://perma.cc/S3ZNDSQB].

78. CHILD TRENDS, supra note 7; see also Neal Halfon et. al., Income Inequality and the Differential Effect of Adverse Childhood Experiences in US Children, 17 ACADEMIC PEDIATRICS 7S (Sept.-Oct. 2017).

79. Burke et al., supra note 44, at 411; see also Christina D. Bethell et al., Adverse Childhood Experiences: Assessing the Impact on Health and School Engagement and the Mitigating Role of Resilience, 33 HEALTH AFFAIRS 2106, 2109 (2014) (conducting a nationwide study finding that 48\% of U.S. children have had at least one ACE); Matthew Kliethermes et al., Complex Trauma, 23 CHILD \& Adolescent Psychiatric Clinics N. AM. 339, 341 (2014).

80. ChILD TRENDS, supra note 7, at 158 .

81. Burke et al., supra note 44.

82. Bethell et al., supra note 79 , at 2110 . The effect remained even after adjusting for demographic and health status factors.

83. Three percent of participants with an ACE score of zero had learning/behavior problems, while $51.2 \%$ of participants with an ACE score of four or more displayed learning/behavior problems. Burke et al., supra note 44 .

84. Troutt, supra note 63, at 614; see also Nat'1 Sci. Council on the Developing Child, Persistent Fear and Anxiety Can Affect Young Children's Learning and Development 8 (Center on the Developing Child, Harv. Univ., Working Paper No. 9, 2010) [hereinafter Persistent Fear], https:/46y5eh11fhgw3ve3ytpwxt9r-wpengine.netdnassl.com/wp-content/uploads/2010/05/Persistent-Fear-and-Anxiety-Can-Affect-Young-Childrens-Learning-andDevelopment.pdf [https://perma.cc/U4UB-EECJ]. 
development. ${ }^{85}$ Several potential causes exist, including poor nutrition, prenatal substance abuse, and increased exposure to toxins. ${ }^{86}$ In addition, poor children tend to be raised in homes with less cognitive stimulation (fewer books, educational toys, and opportunities for educational experiences). ${ }^{87}$ While science has yet to establish a causal effect between poverty and cognitive deficits, a number of studies have established that environment and experience can impact cognitive development. ${ }^{88}$

Children living in neighborhoods of concentrated and chronic poverty are at higher risk for experiencing toxic stress because their risk of exposure to traumatic events is increased. ${ }^{89}$ One example is an increased risk of exposure to community violence. While violence is certainly not present in all low-income communities, nor is it limited to such communities, isolated communities battling chronic poverty also struggle with higher incidence of violence. ${ }^{90}$ Several studies have evidenced the many negative impacts resulting from youth exposure to community violence, including the following: posttraumatic stress disorder (PTSD), anxiety, depression, and dissociation, as well as lower capacity for empathy, and diminished self-esteem. ${ }^{91}$ One study found that "[y]outh exposed to violence have decreased social competence and increased rates of peer rejection, as well as decreased IQ and reading ability, lower gradepoint average (GPA), more days of school absence, and decreased rates of high school graduation." 92

Recently, two separate class-action lawsuits have attempted to leverage this research to claim children growing up in impoverished and violent communities should be considered disabled within the meaning of disability

85. Martha J. Farah et al., Poverty, Privilege, and Brain Development: Empirical Findings and Ethical Implications, in NeUROeTHICs: DefinING THE IsSUES IN THEORY, PRACTICE, AND PoliCy (Judy Illes ed., 2004); see, e.g., Richard Monasterksy, Researchers Probe How Poverty Harms Children's Brains, CHRON. HIGHER EDUC., Feb. 29, 2008, (describing new research attempting to identify the environmental factors associated with living in poverty that have a negative effect on cognitive development).

86. James E. Ryan, Poverty as Disability and the Future of Special Education Law, 101 GEO. L.J. 1455,1483 (2013).

87. Id.

88. Anandi Mani et al., Poverty Impedes Cognitive Function, 341 SCI. 976 (2013).

89. Corina Graif et al., Urban Poverty and Neighborhood Effects on Crime: Incorporating Spatial and Network Perspectives, 8 Soc. ComPASS 1140 (2014); see also Matthew R. Lee, Concentrated Poverty, Race and Homicide, 41 Soc. Q. 189 (2000).

90. Graif et al., supra note 89; see also Lee, supra note 89.

91. Eugene Aisenberg \& Ferol E. Mennen, Children Exposed to Community Violence: Issues for Assessment and Treatment, 17 CHILD \& ADOLESCENT SoC. WoRK J. 341, 344 (2000); Sheryl Kataoka et al., Effects on School Outcomes in Low-Income Minority Youth: Preliminary Findings from a Community-Partnered Study of a School Trauma Intervention, 21 ETHNICITY \& DISEASE S1-71, S171 (2011); Jeff Grogger, Local Violence, Educational Attainment, and Teacher Pay (Nat'1 Bureau of Econ. Research, Working Paper No. 6003, 1997).

92. Kataoka et al., supra note 91. 
rights laws. ${ }^{93}$ In seeking eligibility as students with disabilities under these laws, the suits aimed to access the concomitant rights to special education and related supports and services. ${ }^{94}$ The following sections will provide an overview of relevant disability rights laws and then walk through the legal theories that weave ACEs and disability laws together into class action litigation seeking broad-based educational reforms.

\section{B. The Laws: An Overview of Disability Rights Laws}

Three laws govern the education of students with disabilities in public schools: the Individuals with Disabilities Education Act (IDEA) ${ }^{95}$ Section 504 of the Rehabilitation Act of $1973,{ }^{96}$ and Title II of the Americans with Disabilities Act (ADA) ${ }^{97}$ While the laws certainly interact with each other, there are some distinct differences. The IDEA applies only to children and creates the most affirmative rights for students with disabilities in schools. ${ }^{98}$ Section 504 and the ADA are broader antidiscrimination laws that protect all qualifying individuals with disabilities in a variety of public settings, including public schools. ${ }^{99}$ Section 504 and the ADA are often thought of as protecting negative rights, since they promise the right to be free from discrimination; but they, too, contain important affirmative rights for students with disabilities including the right to accommodations and special education when necessary to ensure equal access to education. ${ }^{100}$ The following section will briefly describe each law and explain how a student becomes eligible for statutory protections under each.

\section{The Individuals with Disabilities Education Act}

The IDEA operates much like a contract in which the federal government promises funding to schools who agree to abide by the law's proscriptions

93. Stephen C. v. Bureau of Indian Educ., No. CV-17-08004-PCT-SPL, 2018 WL 1871457 (D. Ariz. Mar. 29, 2018); P.P. v. Compton Unified Sch. Dist., 135 F. Supp. 3d 1098 (C.D. Cal. 2015).

94. Id.

95. 20 U.S.C. $\$ \$ 1400-1485$ (2012).

96. 29 U.S.C. $\$ 794$ (2012).

97. 42 U.S.C. $\S \S 12101-12213$ (2012).

98. 20 U.S.C. $\S \S 1400-1485$; see generally LAURA ROTHSTEIN \& SCOTT F. JOHNSON, SPECIAL EDUCATION LAW (4th ed. 2010).

99. See generally ROTHSTEIN \& JOHNSON, supra note 98, at 287-99. Section 504 and the ADA are similar in terms of eligibility for protections, but the ADA is much more expansive in that it does not only reach recipients of federal funding.

100. 42 U.S.C. $\S 12182 ; 34$ C.F.R. $\S 104.33$ (2019). 
regarding the treatment of students with disabilities. ${ }^{101}$ In order to be eligible for IDEA services, a child must meet the statute's definition of a "child with a disability" - meaning the child must fall into one of the thirteen recognized categories of disability, the disability must adversely impact education, and the child must need special education and related services as a result. ${ }^{102}$ The IDEA's disability categories are legal, not medical, definitions of disability and they are not without controversy. ${ }^{103}$

The IDEA's purpose is to ensure that all children with disabilities receive special education and related services designed to meet their "unique" needs. ${ }^{104}$ Once a child meets the statutory definition of a "child with a disability," they are entitled to a Free Appropriate Public Education (FAPE). ${ }^{105}$ The Supreme Court has interpreted this to mean an "individualized education program" (IEP) reasonably calculated to enable a child to make progress appropriate in light of the child's circumstances. ${ }^{106}$ IDEA eligible students also have a right to education in the least restrictive environment as well as a number of due process rights. ${ }^{107}$

The law also obligates schools to affirmatively seek out children suspected of having a disability and in need of special education. ${ }^{108}$ This obligation is known as child find and is quite expansive. ${ }^{109}$ Schools typically fulfill this obligation by enacting policies to help screen all

101. See generally 20 U.S.C. $\S \S 1400-1485$ (federal statute governing the rights of eligible students with disabilities in schools).

102. 20 U.S.C. $\S 1401(3)$ (2012); 34 C.F.R. $\S 300.8$.

103. See Mark Weber, The IDEA Eligibility Mess, 57 BufFalo L. REV. 83, 91-92, 122-52 (2009). Intellectual disability, emotional disturbance, and specific learning disability are subjectively measured and thus, prone to bias on the part of evaluators, as evidenced by the over-representation of minority children who make up these categories. Robert A. Garda, Jr., The New IDEA: Shifting Educational Paradigms to Achieve Racial Equality in Special Education, 56 ALA. L. REV. 1071 (2005); see also Theresa Glennon, Race, Education, and the Construction of a Disabled Class, 1995 WIS. L. REV. 1237 (1995). If, by virtue of eligibility for special education services, students improved their educational outcomes, such over-representation would warrant minimal concern. Unfortunately, data illustrates that students with special education needs (and particularly students receiving services under the category of emotional disturbance) achieve markedly less educational success. SHARON VAUGHN ET AL., DEEPER LEARNING FOR StUdents WITH DisabiLITIES 3 (2015), https://files.eric.ed.gov/fulltext/ED560790.pdf [https://perma.cc/GD3L-9YRM] (“According to the most recent [National Assessment of Educational Progress] (NCES 2013), 38-45 percent of students without disabilities performed at the proficient level or above in reading and mathematics in fourth and eighth grade, while a mere 8-17 percent of students with disabilities did so . ...").

104. 20 U.S.C. $\S 1400(d)$ (purposes).

105. 20 U.S.C. $\S \S 1401(9)$ (FAPE definition); § 1401(3) (child with a disability).

106. Endrew F. ex rel. Joseph F. v. Douglas Cty. Sch. Dist. RE-1, 580 U.S. _, 137 S. Ct. 988,991 (2017)

107. 20 U.S.C. $\S 1412(\mathrm{a})(5)$ (least restrictive environment); Id. $\S 1415$ (procedural safeguards).

108. Id. $\S 1412(\mathrm{a})(3)$.

109. Id. 
students for any deviations from normal child development. ${ }^{110}$ The results of such screenings may indicate a problem that warrants further investigation. ${ }^{111}$ When this happens, the IDEA demands individualized comprehensive assessments to determine whether a child qualifies for services under the statute and, if so, the particular services and supports needed to progress in school. ${ }^{112}$ Courts have not reached a clear consensus regarding when a school will be held liable for failure to timely identify a child with a disability. ${ }^{113}$ Some courts hold schools liable for child find violations when they "overlook[] 'clear signs of disability' ... [were] "negligent in failing to order testing," or when there appears to be "no rational justification for not deciding to evaluate." 114

The IDEA clearly provides important substantive and procedural protections for students who meet the law's definition of a "child with a disability." The likelihood that a child impacted by ACEs will be able to meet this definition will largely be dependent on the individual child's circumstances. ${ }^{115}$

\section{Section 504 of the Rehabilitation Act and Title II of the Americans with Disabilities Act}

In contrast to the IDEA, Section 504 and the ADA offer broader coverage as they apply to all individuals, not just students, who meet the statutes' relevant definitions of disability and because that definition itself is expansive. ${ }^{116}$ Section 504 was the first federal statute to prohibit discrimination against the disabled, stating, "[n]o otherwise qualified individual with a disability... shall, solely by reason of her or his disability, be excluded from the participation in, be denied the benefits of, or be subjected to discrimination under any program or activity receiving

110. Typical screenings include hearing and vision screens. State-wide achievement tests can also be used to screen for deviations from the average. ROTHSTEIN \& JOHNSON, supra note 98, at 86.

111. Id.

112. 20 U.S.C. $§ 1414($ b)(2)(A)(i)-(ii). Importantly, these evaluations must use a variety of assessment tools and cannot rely on one single measure, such as a child's full-scale intelligent quotient, to determine eligibility for special education. Id. $\S 1414(\mathrm{~b})(2)(\mathrm{B})$.

113. Perry A. Zirkel, Child Find: The "Reasonable Period" Requirement, 311 EDUC. L. REP. 576, 577-78 (2015) (discussing varying courts' approaches to determining when a school has complied with evaluation of the child within a "reasonable period").

114. Demarcus L. v. Bd. of Educ. of Chi., No. 13 C 5331, 2014 WL 948883, at*5 (N.D. Ill. Mar. 11, 2014) (quoting Bd. of Educ. of Fayette Cty. v. L.M., 478 F.3d 307, 313 (6th Cir. 2007)); see also D.G. v. Flour Bluff Indep. Sch. Dist., 481 F. App'x 887 (5th Cir. 2012); Sch. Bd. of Norfolk v. Brown, 769 F. Supp. 2d 928, 942-43 (E.D. Va. 2010); Perry A. Zirkel, "Child Find”: The Lore v. The Law, 307 EDUC. L. REP. 574 (2014).

115. Eligibility for such a child is discussed further in section II.B.

116. 29 U.S.C. $§ 794(a)$ (2012); 42 U.S.C. § 12131(2) (2012). 
Federal financial assistance ...." ${ }^{117}$ Despite this broad language, Section 504 was largely unenforced and thus, proved ineffective at eradicating disability discrimination. ${ }^{118}$ In response, the ADA was enacted in 1990 to "provide a clear and comprehensive national mandate for the elimination of discrimination against individuals with disabilities." 119 Title II of the ADA was based in large part on Section 504, with Title II regulations patterned after Section 504 regulations. ${ }^{120}$ Both operate as nondiscrimination statutes and bar organizations from discriminating against persons with disabilities for reasons related to their disabilities. ${ }^{121}$ Section 504 is limited to any program or activity receiving federal funds and Title II extends this prohibition to all public organizations. ${ }^{122}$ Thus, both statutes apply to public schools.

In addition, both laws define disability as (1) "a physical or mental impairment that substantially limits one or more of the major life activities"; (2) having "a record of such an impairment"; or (3) "being regarded as having such an impairment." 123 To clarify and expand the law's definition of disability, Congress passed the ADA Amendments Act of $2008 .{ }^{124}$ The expanded definition applies equally to Section $504 .{ }^{125}$

\section{29 U.S.C. $§ 794(a)$.}

118. Timothy M. Cook, The Americans with Disabilities Act: The Move to Integration, 64 TEMP. L. REV. 393, 394, 416 (1991) ("In the ADA, Congress determined, as apparently did the Executive, that section 504 simply was not working as a means of eradicating discrimination and segregation in this country. Congress found that, even though section 504 had been the law for seventeen years, 'society has tended to isolate and segregate individuals with disabilities, and despite some improvements, such forms of discrimination against individuals with disabilities continue to be a serious and pervasive social problem."').

119. 42 U.S.C. §12101(b)(1) (2012); see also Nancy L. Jones, Overview and Essential Requirements of the Americans with Disabilities Act, 64 TEMP. L. REV. 471, 479 (1991).

120. The regulations under Section 504 and the ADA must be "consistent" with each other. 42 U.S.C. $\S 12134$ (b). Further, courts may not construe the provision of the ADA "to apply a lesser standard than the standards applied under [Section 504] or the regulations issued by Federal agencies pursuant" to Section 504. Id. $\S 12201$ (a). Thus, courts generally apply the same analysis to both laws. The regulations pursuant to Title II of the ADA are found at 28 C.F.R. pt. 35, and the regulations under Section 504 are found at 28 C.F.R. pt. $42(\mathrm{G})$.

121. 29 U.S.C. $\S 794$ (2012); 42 U.S.C. $\S 12132$.

122. 29 U.S.C. $\S 794(a) ; 42$ U.S.C. $\S 12132$.

123. 29 U.S.C. $\S 705(20) ; 42$ U.S.C. $\S 12102(1)$.

124. ADA Amendments Act of 2008 (Amendments Act), Pub. L. 110-325, 122 Stat. 3553, 3554 (2008) (codified in scattered sections of 29 and 42 U.S.C.).

125. 42 U.S.C. $\S 12102(4)(A)$. The Amendments Act amended both the ADA and the Rehabilitation Act definition of disability. See 42 U.S.C. § 12101; 154 CoNG. REC. S8342, 8346 (daily ed. Sept. 11, 2008) (statement of the Managers to Accompany S. 3406); see also RUSSLYNN Ali, Assistant SeC'Y FOR Civil Rights, U.S. DEP'T EDUC., QUESTIONS AND ANSWERS ON THE ADA AMENDMENTS ACT OF 2008 FOR STUDENTS With DisABILITIES ATTENDING PubliC ELEMENTARY AND SECONDARY SCHOOLS (Jan. 19, 2012) [hereinafter Attending Public Elementary], https://www2.ed.gov/about/offices/list/ocr/docs/dcl-504faq-201109.pdf [https://perma.cc/7GJZGRNV]; Dear Colleague Letter from Russlynn Ali, Assistant Sec'y, Office for Civil Rights, U.S. 
Consequently, the definition of disability under Section 504 and the ADA is substantially broader than that under the IDEA and thus, generally speaking, a child who is eligible for services under the IDEA will usually qualify for services under either Section 504 or Title II of the ADA. ${ }^{126}$

Both Section 504 and the ADA convey important affirmative rights to students in public schools. ${ }^{127}$ Like the IDEA, they obligate schools to find children with disabilities who need special education or related services and confer FAPE. ${ }^{128}$ But, both child find and FAPE obligations differ from those set forth in the IDEA, however. ${ }^{129}$ For instance, Section 504 defines FAPE in terms of equality of access to education. ${ }^{130}$ It ensures access, but not outcome. ${ }^{131}$ The IDEA's FAPE standard is not based on equal access, but rather calibrated to each individual student's potential, mandating individualized education programs (IEPs) designed to ensure progress towards highly individualized goals. ${ }^{132}$ These distinctions may become important in determining what a school district owes a child with a disability under each law, but courts have only recently begun to recognize the differences. ${ }^{133}$

What is certain, however, is that children who are eligible under either the IDEA, Section 504, or the ADA have the ability to assert their rights in

Dep't of Educ., to Title IX Coordinators (Jan. 19, 2012) [hereinafter Dear Colleague ADA Letter], www.ed.gov/ocr/letters/colleague-201109.html [https://perma.cc/YT4N-XWDH].

126. Weber, supra note 35, at 5-9, 19.

127. 34 C.F.R. $\S 104.36$ (2019) (Procedural safeguards).

128. 34 C.F.R. $\S \S 104.32-.35$; 42 U.S.C. $\S 12134(b)$.

129. 34 C.F.R. $\S 104.33(a)-(b)(1)$. While the ADA does not address child find or FAPE specifically, the U.S. Department of Education has interpreted the ADA's obligations to students as coextensive with that of Section 504. Thus, it has stated that the ADA requires a district to provide FAPE to the same extent as is required under Section 504 in order to comply with the ADA. See Letter from Gary D. Jackson, Dir., Office for Civil Rights, W. Div. Seattle (Washington), Issaquah (WA) School District No. 411, to Janet Berry, Superintendent, Issaquah School District No. 411 (May 2, 2003) (on file with author); Letter from Stella B. Klugman, Team Leader, Office for Civil Rights, W. Div., San Francisco (California), Pleasant Valley (CA) Elementary Sch. Dist., to James Shroyer, Superintendent, Pleasant Valley Elementary Sch. Dist. (June 29, 1999) (on file with author); Letter from Nicole Huggins, Deputy Chief Reg. Att'y, Office for Civil Rights, W. Div. Denver (Arizona), Naco (AZ) Elementary Sch. Dist. No. 23, to Patricia Marsh, Superintendent, Naco Elementary Sch. District No. 23 (Oct. 3, 2006) (on file with author); Letter from Janette J. Lim, Dir. of Pol'y, Enf't, and Program Service, Office for Civil Rights, E. Div. of Philadelphia, to Hon. Nick J. Rahall, House of Representatives, Washington, D.C. (June 22, 1994) (on file with author).

130. 34 C.F.R. $\S 104.33(b)(1)$.

131. Mark H. v. Lemahieu, 513 F.3d 922, 933 (9th Cir. 2008).

132. Endrew F. ex rel. Joseph F. v. Douglas Cty. Sch. Dist. RE-1, 580 U.S. _, 137 S. Ct. 988,999 (2017); see also Bd. of Educ. Hendrick Hudson Cent. Sch. Dist. v. Rowley, $4 \overline{58}$ U.S. 176 (1982).

133. Mark H., 513 F.3d at 933 ("FAPE under the IDEA and FAPE as defined in the $\S 504$ regulations are similar but not identical .... The most important differences are that, unlike FAPE under the IDEA, FAPE under $\S 504$ is defined to require a comparison between the manner in which the needs of disabled and non-disabled children are met, and focuses on the 'design' of a child's educational program.”). 
order to ensure their access to education. In the case of the IDEA, students with disabilities have the right to a substantive standard of education —one that allows them reasonable progress in light of their individual capabilities. Section 504 and the ADA give students with disabilities the right to equal access of education, commensurate to their non-disabled peers. Further, each law provides students with an ability to invoke these protections through due process procedures. The laws give students with disabilities the ability to challenge eligibility, placement, or provision of special education or related services and thus, these students can hold schools accountable in ways that other students cannot. The following section will explore two recent communities that attempted to leverage disability rights laws into agents of broad-based educational reforms.

\section{The Strategy: Combining Science and Disability Laws to Reform Sub-Standard Schools}

In two recent and innovative cases, entire communities of children invoked disability rights laws to demand systemic reforms to the delivery of education for all students - both disabled and non-disabled. The first case involved children from Compton, California, and the second involved a community of Native Americans from the Havasupai Nation. ${ }^{134}$ Both began as class-action lawsuits claiming that children in these communities faced numerous and persistent ACEs that impacted their ability to succeed in school, ${ }^{135}$ and that school districts were aware of these challenges and should have implemented accommodations and other supportive services to address them. ${ }^{136}$ The following section will introduce these groundbreaking cases and explore how their case theories may dramatically re-purpose disability rights statutes into agents of educational reform.

In 2015, a group of students and teachers who attended and taught in the Compton School District in California filed a class-action lawsuit alleging that the school district violated Section 504 and the ADA by failing to timely identify and provide necessary accommodations for students impacted by "complex trauma." 137 The lawsuit defined "complex

134. Stephen C. v. Bureau of Indian Educ., No. CV-17-08004-PCT-SPL, 2018 WL 1871457 (D. Ariz. Mar. 29, 2018); P.P. v. Compton Unified Sch. Dist., 135 F. Supp. 3d 1098 (C.D. Cal. 2015).

135. Stephen C. Complaint, supra note 9, 19 177-178; P.P. Complaint, supra note 9, at 20. While the Compton case is a class action lawsuit invoking the rights of all students who may have attended Compton Unified School District, the Havasupai case was limited to the nine named plaintiffs. However, both sets of plaintiffs sought system-wide educational reforms as a remedy. The underlying question in both, is whether the law requires such a remedy.

136. Stephen C. Complaint, supra note 9, ๆๆ 224-225; P.P. Complaint, supra note 9, at 65-69.

137. P.P. Complaint, supra note 9, at 69. 
trauma" as exposure to multiple persistent sources of violence, loss, and other ACEs. ${ }^{138}$ Plaintiffs pointed to well-known challenges that growing up in Compton brought, including poverty and high incidences of violence, to argue that the school district should have been aware of the likelihood that many of their students were suffering from complex trauma. ${ }^{139}$ As a result of this alleged complex trauma, the plaintiffs asserted they were individuals with disabilities who required specialized supports and services to meaningfully access education. ${ }^{140}$

Just a year later, a similar class-action suit was filed on behalf of nine Native American students who lived on the Havasupai Indian Reservation and attended public schools operated by the Bureau of Indian Education (BIE).${ }^{141}$ Plaintiffs there alleged that the BIE "knowingly failed to provide basic general education, a system of special education, and necessary wellness and mental health support to Havasupai students, resulting in indefensible deficits in academic achievement and educational attainment." $" 142$ Just as in the Compton case, plaintiffs invoked Section 504 regulations to claim that exposure to ACEs and complex trauma provided the basis for eligibility as individuals with disabilities under Section 504. ${ }^{143}$ They argued that the BIE violated Section 504 by failing to identify these children as individuals with disabilities and provide them with necessary supports. ${ }^{144}$

Children from both communities experience the impacts of poverty, community violence, and significant family disruptions at alarmingly high

138. P.P. Complaint, supra note 9 , $\mid 1$. Plaintiffs alleged that $24.6 \%$ of children living in Compton have two or more ACEs. Memorandum of Points and Authorities in Support of Motion for Preliminary Injunction at 2, P.P. v. Compton Unified Sch. Dist., 135 F. Supp. 3d 1098 (C.D. Cal. 2015).

139. See P.P. Complaint, supra note 9, at 19-20, 65.

140. Id. at 23 .

141. Stephen C. v. Bureau of Indian Educ., No. CV-17-08004-PCT-SPL, 2018 WL 1871457 (D. Ariz. Mar. 29, 2018).

142. Stephen C. Complaint, supra note 9 , $\mid 2$.

143. Plaintiffs define "complex trauma" using virtually identical language to the Compton plaintiffs, stating, "Complex trauma stems from the exposure to multiple persistent sources of violence, loss, and other adverse childhood experiences ('ACE's'), and describes children's exposure to these events and the impact of [such] exposure." P.P Complaint, supra note 9, at $1 \mathrm{n} .1$; see Stephen C. Complaint, supra note 9, at 61-62.

144. Plaintiffs' second amended complaint contained six causes of action, four of which were brought under Section 504 and its implementing regulations as follows: (1) failure to provide a system enabling students with disabilities access to public education; (2) failure to provide a system enabling students impacted by childhood adversity to access public education; (3) failure to implement Section 504's "location and notification" regulation; and (4) failure to implement Section 504's "procedural safeguards" regulation. Second Amended Complaint for Declaratory and Injunctive Relief at 50-62, Stephen C. v. Bureau of Indian Educ., 2018 WL 1871457 (D. Ariz. Mar. 29, 2018) (No. 3:17-cv08004-SPL). 
levels. ${ }^{145}$ Thus, in each case, by virtue of being a member of a particular community, a child is more likely to experience neurobiological effects of complex trauma resulting in impaired ability to perform activities essential to education including learning, thinking, reading, and concentrating. ${ }^{146}$ Litigants in both suits invoked disability rights laws to make two claims. First, that by virtue of being a member of their community, they were "individuals with disabilities" and, as such, entitled to a FAPE which includes any special education or related services necessary to ensure equal access to education. ${ }^{147}$ Second, that school districts violated child find obligations by failing to affirmatively identify them as children with disabilities and appropriately accommodate their needs. Such failure, they argued, amounted to disability discrimination. ${ }^{148}$

Both also sought systemic relief in the form of declaratory relief and mandatory injunctions to institute district wide trauma sensitive practices. ${ }^{149}$ The plaintiffs' desired remedies included the following: (1) training educators to recognize, understand, and address the effects of complex trauma, in part through building students' self-regulation and social-emotional learning skills; (2) developing restorative justice practices to resolve conflicts peacefully and avoid re-traumatizing students through the use of punitive discipline; and (3) ensuring that consistent mental health support is available to appropriately meet student needs. ${ }^{150}$ Critically, these remedies require schools to make potentially

145. In this context, family disruptions refer to children being removed from the home and placed in foster care, parents being forcibly removed from the home due to arrest, or one parent needing to leave the home to seek employment elsewhere. Stephen C. Complaint, supra note 9, 9 ๆ 14-37, 16370 .

146. Compton plaintiffs also argued that students impacted by complex trauma were less able to conform their behavior to school expectations and consequently, more likely to face discipline and school exclusion. P.P. Complaint, supra note 9, at 5. Thus, they argued that the school district not only failed to accommodate students impacted by complex trauma, but that it also engaged in districtwide punitive disciplinary policies that re-triggered students' trauma-induced disabilities. Id.

147. Id. at 23; Stephen C. Complaint, supra note 9, ๆ 14-37, 163-70. Each lawsuit also proceeded with claims under other statutes as well. The Compton students alleged an ADA violation using the same facts that supported their Section 504 claim, but Havasupai students did not. P.P Complaint, supra note 9, at 71-72. The Havasupai students brought a number of claims under federal statutes and regulations mandating that the BIE provide an education to Native American children that meets basic educational standards and enables students to access post-secondary educational opportunities. Stephen C. Complaint, supra note 9, $1 \uparrow$ 195-271; see also 25 U.S.C. $\S 2000,2001$ (2012); 25 C.F.R. $\S 32.3-32.4$ (2019).

148. Stephen C. Complaint, supra note 9, at 91-93; P.P. Complaint, supra note 9, at 65, 69.

149. Stephen C. Complaint, supra note 9, at 99-100; P.P. Complaint, supra note 9, at 72-73.

150. P.P. Complaint, supra note 9 , at $72-73$. Havasupai plaintiffs sought a number of system-wide reforms including,

(1) comprehensive and ongoing training, coaching and consultation for all adult staff regarding trauma-informed and culturally sensitive strategies for educating students and fostering a healthy, supporting environment; (2) implementation of restorative practices to prevent, address, 
significant changes to the current curriculum by adopting teaching of social-emotional skills as well as restorative justice practices. Further, the remedies demand such practices be adopted school-wide and not limited to only those students with a demonstrated need for such supports.

At the time of this writing, both cases have survived motions to dismiss. Parties in the Compton case are engaged in out-of-court settlement, while the Havasupai case has completed discovery. ${ }^{151}$ Consequently, the question of whether a child impacted by ACEs is an individual with a disability, thereby receiving attendant rights under disability rights laws, remains unanswered. A court may ultimately adopt the Compton School District's argument that while the "blight of all 'socioeconomically distressed cities' throughout America is rightfully a major concern ... [p]laintiffs cannot ... fashion[] those issues into a question of disability rights." 152 Courts may also be concerned about judicial overreach and effectively legislating educational policy from the bench. ${ }^{153}$

These lawsuits are groundbreaking for two distinct and equally important reasons. First, they have the potential to expand the eligibility of students with disabilities to include entire neighborhoods of children

and heal after conflict; (3) employment of appropriately trained counselors who can assist with identification of students who have mental-health difficulties; (4) adoption of practices and interventions to enhance student wellness that are responsive to Havasupai beliefs and traditions and are created in partnership with community members.

Second Amended Complaint for Declaratory and Injunctive Relief at 63, Stephen C. v. Bureau of Indian Educ., 2018 WL 1871457 (D. Ariz. Mar. 29, 2018) (No. 3:17-cv-08004-SPL). The Compton plaintiffs requested school-wide trauma sensitive practices with three core components:

(1) training for educators to recognize, understand, and proactively recognize and address the effects of complex trauma, in part through building students' self-regulation and socialemotional learning skills; (2) developing restorative practices to build healthy relationships and resolve conflicts peacefully and avoid re-traumatizing students through the use of punitive discipline; and (3) ensuring consistent mental health support is available to appropriately meet student needs.

P.P. Complaint, supra note 9, at 4.

151. David Washburn, How a Tiny Native American Community's Trauma Might Impact Education Law, EDSOURCE (Apr. 5, 2018), https://edsource.org/2018/how-a-tiny-nativecommunitys-trauma-might-impact-education-law/595719 [https://perma.cc/CV2N-ZC63].

152. Memorandum of Points \& Authorities in Support of Defendants' Motion to Dismiss Plaintiffs' Class Action Complaint Pursuant to Fed. R. Civ. P. 12(b)(6) at 10, P.P. v. Compton Unified Sch. Dist., 135 F. Supp. 3d 1098 (C.D. Cal. 2015) (No. CV 15-3726-MWF (PLAx)). Compton Unified School District argued that finding for Plaintiffs would equate to courts dictating educational policy, something that the Supreme Court has strongly warned against. Defendants' Memorandum of Points and Authorities in Opposition to Plaintiffs' Motion for Preliminary Injunction at 8, P.P., 135 F. Supp. 3d 1098; see infra note 153.

153. The Supreme Court has strongly warned against courts making decisions impacting educational policy, stating that "courts lack the specialized knowledge and experience' necessary to resolve "persistent and difficult questions of educational policy." Bd. of Educ. Hendrick Hudson Cent. Sch. Dist., 458 U.S. at 208 (internal quotation marks omitted) (quoting San Antonio Indep. Sch. Dist. v. Rodriguez, 411 U.S. 1, 42 (1973)); see also Endrew F. ex rel. Joseph F. v. Douglas Cty. Sch. Dist. RE-1, 580 U.S. _, 137 S. Ct. 988, 1001-02 (2017). 
based on geography and neighborhood characteristics. Second, they attempt to reconceptualize the purpose of disability rights statutes into agents of educational reform, impacting educational programs for all students - not just those with disabilities. The following sections explore both issues by first discussing whether ACEs-impacted students could be eligible for statutory protections under the various disability rights laws, and second, by analyzing a theory of class-based systemic relief under those laws.

\section{TESTING THE THEORY: ACES AS DISABILITY}

Categories of disability are ultimately social constructs and-in the case of disability rights laws - legal constructs. Both in medicine and the law, disability labels are ways to describe certain characteristics that appear connected and others that deviate in some way from expected patterns of mental or physical function. ${ }^{154}$ The relevant question for purposes of accessing protections found within disability rights laws is whether each law's respective definition of disability encompasses the physical or psychological impacts brought on by exposure to ACEs. The science supporting the link between ACEs and changes to the stressresponse system make it plausible that some children impacted by ACEs may be eligible for protections under all three laws. Yet, the analysis will differ under each law and will be highly dependent on the individual characteristics of each child. The following section will walk through the eligibility analysis for a child impacted by ACEs and discuss the challenges to eligibility under each law.

\section{A. Eligibility Under Section 504 and the ADA}

As discussed above, Section 504 and Title II of the ADA are explicitly interwoven and determining eligibility under either statute requires largely the same analysis. Thus, the following section will analyze both laws jointly, noting any relevant differences. ${ }^{155}$ To be eligible under either

154. Samuel R. Bagenstos, Subordination, Stigma, and “Disability," 86 VA. L. REV. 397, 428-29 (2000). The "social model" of the modern disability rights movement advocates that disability is not at all a condition of the physical body, but rather the result of an interaction between the body and society.

155. "The remedies, procedures, and rights set forth in [Section 504] shall be the remedies, procedures and rights [applicable to ADA claims]." 42 U.S.C. $§ 12133$ (2012). "There is no significant difference in analysis of the rights and obligations created by the ADA and the Rehabilitation Act." Zukle v. Regents of Univ. of Cal., 166 F.3d 1041, 1045 n.11 (9th Cir. 1999); 28 C.F.R. § 35.103(a) (2019) ("Except as otherwise provided in this part, this part shall not be construed to apply a lesser standard than the standards applied under title V of the Rehabilitation Act of 1973 . . . or the regulations issued by Federal agencies pursuant to that title."). 
statute, a student must have a "physical or mental impairment" that "substantially limits one or more major life activities." ${ }^{156}$ Both prongs of the definition are construed broadly. ${ }^{157}$ The laws do not confine physical or mental impairments to a delineated list and can include any mental or psychological disorder. ${ }^{158}$ Major life activities are also interpreted broadly and while not confined to specific categories, do explicitly include learning, reading, concentrating, thinking, and communicating. ${ }^{159}$ Importantly, a student may be eligible regardless of whether the condition affects learning as long as the condition substantially limits another major life activity. ${ }^{160}$

Section 504 specifically mandates that all children who need, or are believed to need, special education or related services due to a disability receive an evaluation to help assess areas of educational need and to determine placement in the regular or special education setting. ${ }^{161}$ A student seeking Section 504 or ADA eligibility as a result of ACEs must undergo an evaluation designed to root out whether and how such experiences impact a major life activity. ${ }^{162}$ Eligibility is not limited to medically diagnosable conditions, but can also include traits or characteristics understood to be disabling in certain physical or social environments. ${ }^{163}$

156. 29 U.S.C. $\S \S 705(9)(B)$ (2012), (20)(B); 29 U.S.C. $\S 794(a) ; 28$ C.F.R. $\S 35.108(a)(1)(i)$. The Amendments Act amended the Rehabilitation Act's definition of disability to conform it to that of the ADA. The ADA's current definition of disability means, with respect to a person, "a physical or mental impairment that substantially limits one or more of the major life activities; a record of such an impairment; or being regarding as having such an impairment . ..." 28 C.F.R. § 35.108(a)(1).

157. Dear Colleague ADA Letter, supra note 125; Attending Public Elementary, supra note 125.

158. 34 C.F.R. § 104.3(j)(1)-(2)(i); 29 C.F.R. § 1630.2(h) (defining "physical or mental impairment" as "[a]ny physiological disorder or condition, cosmetic disfigurement, or anatomical loss affecting one or more body systems"); see also U.S. DEP'T EDUC., FAQS, supra note 22 (FAQ \# 11).

159. 29 U.S.C. $\S \S 705(9)(b),(20)(B) ; 42$ U.S.C. $§ 12102(2)(A)$ (2018); see also Dear Colleague ADA Letter, supra note 125; Attending Public Elementary, supra note 125.

160. 28 C.F.R. § 35.104; 34 C.F.R. § 104.3(j)(2)(ii); Norfolk (VA) Public Schools, 114 L.R.P. 47372 (Office for Civil Rights, S. Div., D.C. Va. May 16, 2014).

161. 34 C.F.R. $\S 104.35$. The assessment and eligibility process requires schools to "draw upon information from a variety of sources, including ... teacher recommendations, physical condition, social or cultural background" and ensure all information is "documented and carefully considered." $I d$. Thus, when special education or related services are at issue, Section 504 mandates that eligibility determinations are a team decision and that such determinations involve an examination of data from a variety of sources. $I d$.

162. 34. C.F.R. $§ 104.35(a)$; see also OFFICE FOR CIVIL RIGHTS, U.S. DEP’T EDUC., PARENT AND EduCATOR Resource Guide to SECTION 504 In Public ElEMENTARY AND SECONDARy SCHOOLS 12 (2016) [hereinafter PARENT \& EDUCATOR RESOURCE GUIDE], https://www2.ed.gov/about/offices /list/ocr/docs/504-resource-guide-201612.pdf [https://perma.cc/D8GV-Q7V6].

163. A specific diagnosis is not necessary if the school determines a student is substantially limited in a major life activity and that limitation is caused by a mental or physical impairment. 34 C.F.R. $\S \S 104.3(\mathrm{j}), 104.35$; see also OfFiCe FOR Civil Rights, U.S. DeP’T OF EdUC., STUdents with ADHD AND SECTION 504: A RESOURCE GuIDE 23 n.70 (July 2016), attached to Dear Colleague Letter 
While a medical diagnosis is not necessary for eligibility, some objective measure of the disability and its impacts is necessary. ${ }^{164}$ Significant research currently demonstrates the impacts of multiple or sustained ACEs on normal child development, including physical changes to brain development, an altered stress-response system, and out-sized reactions to perceived threats. ${ }^{165}$ Given the enormity of research in the field evidencing harmful impacts from prolonged exposure to stressful experiences, it is likely that many children impacted by ACEs will evidence symptoms that will meet the laws' definition of a "mental disorder." However, it is certainly not true that all children with ACEs will have the same reaction. Thus, individual evaluations to determine ACEs' effects are crucial to determine whether such exposure rises to the level of a mental impairment in any one child. ${ }^{166}$

The second part of the eligibility inquiry asks whether the physical or mental impairment "substantially limits one or more... major life activit[y]." 167 This prong is considered in relation to the average person, not the individual student or their peers. ${ }^{168}$ The relevant question is whether disability impacts an individual's ability to perform a major life activity as compared to most people in the general population. Given the broad interpretation of disability that Congress insisted upon in the ADA Amendments Act of 2008, many students living with toxic stress will meet this prong with ease. ${ }^{169}$ The research focused on ACEs demonstrates effects

from Catherine E. Lhamon, Assistant Sec'y, Office for Civil Rights., U.S. Dep't of Educ., to Title IX Coordinators (July 26, 2016), available at www.ed.gov/ocr/letters/colleague-201607-504-adhd.pdf [https://perma.cc/ZKV7-2WRP]; Bagenstos, supra note 154, at 428-29.

164. 34 C.F.R. § 104.35; see also U.S. DEP’T EDUC., FAQs, supra note 22 ( FAQ \#11).

165. Metzler et al., supra note 51 (citing several studies within this paper); Shonkoff et al., supra note 52 .

166. Nat'l Child Traumatic Stress Network, Complex Trauma Standardized MEASURES, https://www.nctsn.org/resources/complex-trauma-standardized-measures

[https://perma.cc/2AFL-4DES]; see also KATIE EKLUND \& ERIC ROSSEN, NAT'L CTR. FOR MENTAL

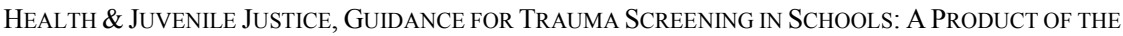
DEFENDING ChILDHOOD STATE PoliCy Initiative (2016), https://www.nasponline.org/x37269.xml [https://perma.cc/SD8X-L26P] (discussing the benefits of implementing universal screenings as an essential component of multi-tiered systems of support).

167. 28 C.F.R. $\S 35.108(a)(1)(i)$ (2019).

168. See, e.g., Weidow v. Scranton Sch. Dist., 460 F. App’x 181, 185 (3d Cir. 2012).

169. Despite the federal guidance, the substantially limits prong may still constrain eligibility by requiring students to demonstrate that complex trauma impacts a major life activity more than the average person. A few courts have found students' claims lacking for failing to meet the substantially limits prong when factually specific information describing the disability's impacts was not present or did not appear severe or frequent. Mann v. La. High Sch. Athletic Ass'n, 535 F. App'x 405, 41112 (5th Cir. 2013) (finding doctor's note diagnosing a student with anxiety disorder insufficient to meet the substantially limits prong); Weidow, $460 \mathrm{~F}$. App'x at 185-86 (finding that a student with bipolar disorder failed to present sufficient evidence of substantial impact of the disorder's effects on 
on attention, memory, learning and executive functioning. ${ }^{170}$ This research supports the idea that children impacted by multiple ACEs are disadvantaged in ways that their peers, who have not had such experiences, are not. ${ }^{171}$ Further, some impacts of ACEs including learning and concentrating are specifically listed as major life activities in the ADA. ${ }^{172}$

In short, Section 504 and the ADA permit an expansive understanding of what can qualify as a disabling condition. Students suffering from impacts of toxic stress will likely be able to find refuge in the laws' protections. While the eligibility under both laws is theoretically available to these students, individual eligibility determinations are required. Importantly, eligibility is not based on one single test or diagnosis, but rather involves a team decision. ${ }^{173}$ Thus, it will be crucial for school officials to be aware of the research behind ACEs and the resulting impacts on development and behavior in order to make the connection between exposure to ACEs and impacts on learning, behavior, and/or other major life activities.

\section{B. Eligibility Under the IDEA}

The IDEA sets much narrower parameters around who is considered a "child with a disability" and as such, eligible for statutory protections. ${ }^{174}$ The IDEA limits eligibility to thirteen categories of disability. ${ }^{175}$ Each category represents a legal — not medical — definition of disability, and further instructs that the disability must adversely impact the child's educational performance. ${ }^{176}$ Courts have interpreted educational performance broadly to include non-academic skills such as behavior and peer relationships. ${ }^{177}$ Courts have also interpreted "advers[ity]" to mean any negative effect and have rejected schools' attempts to frame this requirement as "significant" or "substantial" adversity. ${ }^{178}$ Finally, in order to be eligible for statutory protections, under the IDEA a child must

\footnotetext{
her interactions with others despite presenting evidence of peer relationship troubles).

170. Shonkoff et al., supra note 52.

171. See supra section I.A.3.

172. 42 U.S.C. $\S 12102(2)(A)(2012)$.

173. 34 C.F.R. $\S 104.35(c)(2019)$.

174. 20 U.S.C. $\$ 1401(3)(A)(2012)$.

175. Id.

176. Id.

177. Mr. I. ex rel. L.I. v. Me. Sch. Admin. Dist. No. 55, 480 F.3d 1 (1st Cir. 2007) (holding that a school improperly denied IDEA eligibility to a child with Asperger's Syndrome and depressive disorder whose needs were social and emotional but not academic).
}

178. Id. at 13. 
require special education and related services as a result of the disability. ${ }^{179}$ All three prongs present obstacles to eligibility for students impacted by ACEs.

Of the IDEA's thirteen disability categories, students suffering the effects of toxic stress will most likely be classified under "emotional disturbance." ${ }^{180}$ As one court of appeals aptly described, this category identifies "a class of children who are disabled only in the sense that their abnormal emotional conditions prevent them from choosing normal responses to normal situations." 181 Emotional disturbance encompasses conditions that occur over a long period of time and to a marked degree. Such conditions are evidenced by certain characteristics, including inability to maintain appropriate relationships with teachers or peers, inappropriate behavior or feelings under normal circumstances, a general pervasive mood of unhappiness or depression, or a tendency to develop physical symptoms or fears associated with personal or school-related problems. ${ }^{182} \mathrm{~A}$ child impacted by ACEs may certainly manifest behaviors that could fit several of the delineated characteristics. In fact, research on the impacts of ACEs evidences a probability of heightened fears under normal circumstances, and a child with heightened fight or flight responses could certainly have trouble maintaining relationships with peers or teachers. ${ }^{183}$ However, eligibility must include a professional assessment that evidences ACEs' impacts to a "marked degree." 184 Thus, many children who are impacted by ACEs to some degree may not demonstrate behaviors that manifest severely enough to qualify under this category. ${ }^{185}$

179. 34 C.F.R. § 300.8(a)(1) (2019). A student needs special education and related services when the student requires those services in order to receive an educational benefit from the educational program. Mr. I. ex rel. L.I., 480 F.3d 1; Sebastian M. v. King Philip Reg'l Sch. Dist., 685 F.3d 79 (1st Cir. 2012); Marshall Joint Sch. Dist. No. 2 v. C.D. ex rel. Brian D., 616 F.3d 632 (7th Cir. 2010).

180. 34 C.F.R. $\S 300.8(c)(4)(i)$.

181. Indep. Sch. Dist. No. 284 v. A.C., 258 F.3d 769, 775-76 (8th Cir. 2001).

182. 34 C.F.R. $\S 300.8(c)(4)(i)$. Emotional Disturbance is a condition exhibiting one or more of the five enumerated characteristics "over a long period of time and to a marked degree." Id. The characteristics are as follows: (i) "[a]n inability to learn that cannot be explained by intellectual, sensory or health factors;" (ii) "[a]n inability to build or maintain satisfactory interpersonal relationships with peers and teachers;" (iii) "[i]nappropriate types of behavior or feelings under normal circumstances;" (iv) "[a] general pervasive mood of unhappiness or depression;" and (v) "[a] tendency to develop physical symptoms or fears associated with personal or school problems." Id.

183. Supra section I.A.2.

184. Neither the IDEA statute nor its regulations at 34 C.F.R. $\S 300.8(c)(4)(i)$ define the requirement that a student's qualifying behavior manifest itself "to a marked degree." OSEP has taken the position that it generally refers to the frequency, duration, or intensity of a student's emotionally disturbed behavior in comparison to the behavior of his peers and can be indicative of either degree of acuity or pervasiveness. Letter from Judy A. Schrag, Dir., Office of Special Educ. Programs, to Anonymous (Aug. 11, 1989) (on file with author).

185. While a medical or clinical diagnosis is generally not required in order to be eligible under the 
Even assuming a student clearly exhibits characteristics delineated under emotional disturbance, the student must also demonstrate the need for special education and related services. ${ }^{186}$ The IDEA defines special education as specially designed instruction that adapts content, methodology, or delivery of instruction to address the needs of the child resulting from disability. ${ }^{187}$ Many ACEs-impacted students will need mental health supports, but not necessarily a modification to the delivery, content, or methodology of curriculum. Counseling, psychological, and social work services are generally considered related services, but not special education. ${ }^{188}$ If a child only needs related services, he or she does not meet the IDEA's definition of a "child with a disability." 189

Finally, researchers have long bemoaned the emotional disturbance category as overly broad and prone to subjective bias. Critics argue that African-American students are more likely to be misidentified with emotional disturbance due to culturally-insensitive evaluation procedures. ${ }^{190}$ Further, children labeled with emotional disturbance have among the poorest educational outcomes of any IDEA disability cohort. ${ }^{191}$ Consequently, the value of striving for eligibility under this particular category of disability is dubious, at best.

While there is certainly a path to eligibility and subsequent protections under all three disability rights laws, the IDEA is clearly the trickiest to navigate. Under each law, eligibility is considered on a case-by-case basis,

emotional disturbance category, states can issue their own regulations to further define IDEA disability categories. For instance, South Carolina requires evidence that a child is rated within the highest level of significance on a valid and reliable problem behavior rating scale by both a teacher and another adult knowledgeable of the student; a valid personality measure administered by psychologist or licensed psycho-educational specialist; and documentation that the student's observable school problem behavior occurs at a "significantly different rate, intensity, or duration than [a] substantial majority of typical school peers." MiCK ZAIS, S.C. STATE DEP'T OF EDUC., OFFICE

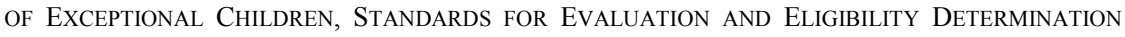
(SEED) (2011).

186. 34 C.F.R. $\S 300.8(a)(1)$.

187. Id. $\S 300.39$.

188. 20 U.S.C. $§ 1401(26)$ (2018); 34 C.F.R. § 300.34; see also Cerra v. Pawling Cent. Sch. Dist., 427 F.3d 186 (2d Cir. 2005).

189. If a child has one of the disabilities identified at 34 C.F.R. $\S 300.8(a)(1)$, but only needs related services and not special education, the child is not a child with a disability under the IDEA. 34 C.F.R. $\S 300.8(\mathrm{a})(2)(\mathrm{i})$. However, if the related service that the child requires is considered "special education" under state standards, the child will be eligible under the IDEA. 34 C.F.R. $\S 300.8(a)(2)$ (ii).

190. Nicole M. Oelrich, A New "Idea": Ending Racial Disparity in the Identification of Students with Emotional Disturbance, 57 S.D. L. REV. 9, 28 (2012) (arguing that the IDEA's definition of emotional disturbance contributes to the over-identification of African-American students under this category of disability).

191. See Mary M. Wagner, Outcomes for Youths with Serious Emotional Disturbance in Secondary School and Early Adulthood, 5 FUTURE CHILD. 90, 97-99 (1995). 
accounting for the reality that exposure to ACEs will impact children differently. For some, ACEs will lead to difficulty concentrating, managing stress, or conforming behavior to expected norms, but this will not be true for all. Schools, of course, only owe statutorily mandated duties to children who meet statutory definitions of disability.

But school districts are also obligated to seek out those students who may have disabilities and determine whether they require special education or related services. The class-action lawsuits that seek school-wide reforms through Section 504 and the ADA claim that schools failed to live up to this duty. Because of schools' failures to identify students with potential disabilities and provide them with necessary supports, plaintiffs argue that schools violated disability rights laws. The following section will turn to the practical questions presented by class-action lawsuits invoking Section 504 and the ADA to demand systemic remedies for the failure to identify ACEsimpacted students as individuals with disabilities.

\section{FLAWS IN THE LEGAL STRATEGY}

Attempting to use ACEs research as the foundation for systemic educational remedies runs into two categories of problems: legal and societal. To overcome legal hurdles, plaintiffs must demonstrate, first, that a school's knowledge of a high probability of ACEs is enough to trigger the school's child find obligation; and, second, that a school's knowledge of this probability is enough to trigger programmatic changes affecting all students. To overcome societal problems, two difficult questions must be answered: (1) does opening the doors of eligibility wide enough to allow entire neighborhoods of children to be labeled "disabled" have unintended negative consequences?; and (2) is the risk of stigma outweighed by the benefits derived from disability rights protections?

\section{A. The Limits of Child Find}

Section 504 represented a "national commitment to eliminate the "glaring neglect of the handicapped" which caused them to "live among society "shunted aside, hidden, and ignored." 192 Congress identified architectural and communication barriers as a central cause of that exclusion. ${ }^{193}$ But Congress also made clear that agencies "charged with administering the Act had substantial leeway to explore areas in which

192. Alexander v. Choate, 469 U.S. 287, 296 (1985) (first quoting 118 ConG. REC. 526 (1972) (statement of Sen. Percy); and then quoting 117 CONG. REC. 45974 (1971) (statement of Rep. Vanik)).

193. Timothy M. Cook, The Scope of the Right to Meaningful Access and the Defense of Undue Burdens under Disability Civil Rights Laws, 20 LOY. L.A. L. REV. 1471 (1987). 
discrimination against the handicapped posed particularly significant problems and to devise regulations to prohibit such discrimination." 194 In the context of education, that meant not only prohibiting discrimination, but also affirmatively welcoming students with disabilities into public schools. Thus, the statute contains a "location and notification" regulation that directs schools to find children in their respective communities who may have disabilities. ${ }^{195}$ Courts often refer to this obligation as "child find" and liken it to a similar obligation found in the IDEA. ${ }^{196}$

Section 504's child find mandate is actually driven by two regulations: the location and notification regulation ${ }^{197}$ (directed at community-wide responsibilities) and the "evaluation and placement" regulation ${ }^{198}$ (directed at an individualized obligation). Class-action suits seeking reforms under disability rights laws rest on schools' child find obligations. ${ }^{199}$ Plaintiffs claim that school districts shirked this duty by failing to properly identify ACEs-impacted students as individuals with disabilities. However, as the following section illustrates, there are limits to Section 504's child find mandate that make class actions based on ACEs exposure tenuous at best.

\section{Child Find: The Obligation to the Community}

Section 504's "location and notification" regulation tasks schools with providing the community, and specifically parents, notice of the law's protections for children with disabilities. ${ }^{200}$ Courts generally hold that expansive messaging through posting on websites, newspapers, and in relevant offices, as well as sending notices to parents of school-aged children, is sufficient to meet this type of community-based obligation. ${ }^{201}$ Similarly, the U.S. Department of Education has given school districts wide latitude in executing the community-wide child find obligation. ${ }^{202}$

194. Alexander, 469 U.S. at 304 n.24 (citing S. REP. No. 93-1297, at 40-41, 56 (1974)).

195. 34 C.F.R. $\S 104.32$ (2019).

196. 34 C.F.R. $\S 300.111$.

197. Id. $\S 104.32$.

198. Id. $\S 104.35$.

199. See infra Part IV.

200. 34 C.F.R. $§ 104.32$ (location and notification) ("A recipient that operates a public elementary or secondary education program or activity shall annually: (a) Undertake to identify and locate every qualified handicapped person residing in the recipient's jurisdiction who is not receiving a public education; and (b) Take appropriate steps to notify handicapped persons and their parents or guardians of the recipient's duty under this subpart.").

201. P.P. ex rel. Michael P. v. W. Chester Area Sch. Dist., 585 F.3d 727, 738 (3d Cir. 2009).

202. Letter to Veir, 20 I.D.E.L.R. 864 (Office for Civil Rights, Southern Div., Dallas (Texas), Dec. 1,1993 ) (stating " $[\mathrm{t}]$ here are many means available including notices to private schools, state and 
The plain language of the regulation only tasks schools with identifying persons who are not currently in public school and who may have rights under the act. ${ }^{203}$ It provides no guidance regarding how schools are to undertake this identification. ${ }^{204}$ As to students with disabilities currently in school, the regulation imparts a duty to "take appropriate steps to notify" those students, and their guardians, of their rights. ${ }^{205}$ It does not demand that schools take any steps beyond notification. ${ }^{206}$ For instance, it does not explicitly task schools with evaluating children suspected of having disabilities to determine whether they would qualify for services.

However, the meaning of child find has evolved since the passage of Section 504 to include a duty to an individualized child who is suspected of having a disability. Courts often cite to the location and notification regulation for support of a broad child find duty that includes an obligation to evaluate individual students suspected of having a disability. However, the support for this individualized duty is contained in a separate regulation, discussed next. ${ }^{207}$

\section{Child Find: The Obligation to the Individual}

The Department of Education points to Section 504's "evaluation and placement" regulation as the catalyst for a school's duty to identify an individual child who may have a disability. ${ }^{208}$ This regulation obligates schools to find individual children who, due to a disability, are "believed to need special education or related services" and directs schools to complete an evaluation of such students before "taking any action with respect to the initial placement of the person in regular or special education." ${ }^{209}$ Importantly, both the plain language of the regulation and agency interpretation limit the obligation to students who may need

local agencies, and notices placed in newspapers").

203. 34 C.F.R. § 104.32.

204. Id.

205. Id. Under an even more restrictive reading of Regulation 34 C.F.R. $\S 104.32$, schools only have the duty to notify those "qualified handicapped persons" who are not receiving a public education of their rights under the statute. $I d$.

206. $I d$.

207. P.P. v. Compton Unified Sch. Dist., 135 F. Supp. 3d 1098, 1119 (C.D. Cal. 2015).

208. 34 C.F.R. § 104.35; see also Dear Colleague ADA Letter, supra note 125; Attending Public Elementary, supra note 125, at Q9 ("A school district must conduct an evaluation of any individual who because of a disability 'needs or is believed to need' special education or related services." (quoting 34 C.F.R. § 104.35)).

209. 34 C.F.R. $\S 104.35$. 
"special education or related services." 210 But, courts and agency interpretations of this regulation do not always align with each other.

Courts interpreting Section 504's child find reach have held that schools must refer a child suspected of having a disability for an evaluation to determine eligibility. ${ }^{211}$ This duty is triggered upon schools being "reasonably suspect[]" of disability. ${ }^{212}$ The law does not explicitly set forth what would constitute "reasonable suspicion" in this context, and thus, courts make case-by-case determinations. ${ }^{213}$ Generally, courts have held that schools can be liable for violating child find when they knew or reasonably should have known of disability. ${ }^{214}$

The U.S. Department of Education, Office for Civil Rights (OCR) ${ }^{215}$ is more nuanced in its interpretation and instructs:

When a school is aware of a student's disability, or has reason to suspect a student has a disability, and the student needs or is believed to need special education or related services, it would be a violation of Section 504 if the school delays or denies the evaluation. ${ }^{216}$

210. Id.; see also Attending Public Elementary, supra note 125, at Q9; Dear Colleague ADA Letter, supra note 125 .

211. D.K. v. Abington Sch. Dist., 696 F.3d 233, 249 (3d Cir. 2012) (“"School districts have a continuing obligation under the IDEA and $\S 504$ '—called 'Child Find' - 'to identify and evaluate all students who are reasonably suspected of having a disability under the statutes." (citing P.P. ex rel. Michael P. v. W. Chester Area Sch. Distr., 585 F.3d 727, 738 (3d Cir. 2009)); D.G. v. Somerset Hills Sch. Dist., 559 F. Supp. 2d 484, 496 (D.N.J. 2008) (refusing to dismiss IDEA-alternative $\S 504$ claim for student with depressive disorder and finding "[i]n establishing a [Section 504] claim, a plaintiff must demonstrate that the defendants knew or should have known about the disability"); see also Zirkel, supra note 114, at 575.

212. P.P. ex rel. Michael P., 585 F.3d at 738 ("School districts have a continuing obligation under the IDEA and $\S 504$ to identify and evaluate all students who are reasonably suspected of having a disability under the statutes." (citing Ridgewood Bd. of Educ. v. N.E. ex rel. M.E., 172 F.3d 238, 253 (3d Cir. 1999), superseded by statute, 20 U.S.C. $\$ 1415(\mathrm{f})(3)(\mathrm{C})$, as recognized in D.F. v. Collingswood Borough Bd. of Educ., 694 F.3d 488 (3d Cir. 2012)); see also Nathanson v. Med. Coll. of Pa., 926 F.2d 1368, 1380 (3d Cir. 1991) (stating that plaintiffs must prove a school knew or should have been reasonably expected to know about plaintiff's disability in order to establish liability under Section 504).

213. Nathanson, 926 F.2d at 1381 ("Neither the Rehabilitation Act nor the regulations specif[y] what notification is necessary to adequately inform a recipient of a person's handicap or what constitutes awareness of a handicap.").

214. W.B. v. Matula, 67 F.3d 484, 493 (3d Cir. 1995), abrogated by A.W. v. Jersey City Pub. Sch., 486 F.3d 791 (3d Cir. 2007) ("[T]o be liable, defendants "must know or be reasonably expected to know of' E.J.'s disability.” (citing Nathanson, 926 F.2d 1368, 1381 (3d Cir.1991))).

215. OCR is the enforcement arm of the U.S. Department of Education and has the authority to enforce several Federal civil rights laws that prohibit discrimination in programs that receive federal funding from the Department of Education, including Section 504 and Title II of the ADA. About OCR, U.S. DEP'T EDUC. OFFICE CIVIL RIGHTS, https://www2.ed.gov/about/offices/list/ocr/ aboutocr.html [https://perma.cc/FM4N-VGNR].

216. PARENT \& EDUCATOR RESOURCE GUIDE, supra note 162, at 12 (emphasis added). 
It bases this interpretation on the combined duties in both the location and notification and evaluation and placement regulations. ${ }^{217}$

OCR indicates that schools' knowledge of an existing disability may not always trigger the need to evaluate if the child does not need special education or related services. ${ }^{218}$ Violations of Section 504's child find mandate occur where schools either knew of the need for an evaluation through a request from a parent or through its own observations indicating that a student has an impairment which impacts academic or behavioral performance. ${ }^{219}$ In guidance documents, OCR explains, "[t]he Section 504 regulation does not set out specific circumstances that trigger the obligation to conduct an evaluation; the decision to conduct an evaluation is governed by the individual circumstances in each case." ${ }^{\text {220 }}$ Consequently, agency guidance suggests liability for child find only attaches when a school should have been reasonably aware of a disability that requires special education or related services, and not-as some courts interpret-an obligation to evaluate with knowledge of disability alone.

Finally, Section 504's child find directive requires schools to refer for evaluation students suspected of having disabilities that require "special education" or "related services," but fails to define either term. The IDEA suggests that "special education" means specially designed instruction adapted to an individual child's needs, and "related services" encompass almost anything needed to help a student with a disability to access FAPE. ${ }^{221}$ Thus, schools must think in broad terms when seeking out students who may require supports and services. ${ }^{222}$

217. See 34 C.F.R. $\S \S 104.32$, 104.35 (2019); U.S. DEP’T EDUC., FAQS, supra note 22 (FAQ\#34).

218. Attending Public Elementary, supra note 125, at Q12. At the same time, academic success or failure is not the only trigger requiring a need to evaluate. Id. at Q9 ("[G]rades alone are an insufficient basis upon which to determine whether a student has a disability. Moreover, they may not be the determinative factor in deciding whether a student with a disability needs special education or related aids or services.").

219. Valley Oaks (CA) Charter Sch., 115 L.R.P. 52093 (Office for Civil Rights, W. Div., Ca., June 29, 2015); Aurora (CO) Pub. Sch., 61 I.D.E.L.R. 83 (Office for Civil Rights, W. Div., Co., Jan. 14, 2013).

220. Attending Public Elementary, supra note 125, at Q9.

221. The IDEA defines special education as "specially designed instruction, at no cost to parents, to meet the unique needs of a child with a disability," 20 U.S.C. § 1401(29) (2012), and "related services" to mean "transportation, and such developmental, corrective, and other supportive services ... designed to enable a child with a disability to receive a free appropriate public education." $\S 1401(26)$. The list of IDEA's related services enumerated in 34 C.F.R. $\S 300.34$ is not exhaustive.

222. For example, related services can include counseling services, transportation, and orientation and mobility services. 34 C.F.R. $§ 300.34$; see also PARENT \& EDUCATOR RESOURCE GUIDE, supra note 162. 


\section{Child Find: The Implications for ACEs}

Science convincingly demonstrates that many children who have experienced ACEs may suffer long-term effects, but does not conclusively demonstrate that all will. Thus, in the context of ACEs, the question is: when is a school deemed to have "reasonable suspicion" of a disability triggering the need to evaluate? The Compton and Havasupai students argued that schools must begin an evaluation process once they are aware of the existence of ACEs, and thus, students should be assessed for eligibility purely based on living in a certain community. ${ }^{223}$ In effect, their claim attempts to broaden eligibility to include exposure to ACEs itself, regardless of the effects of such exposure.

If mere exposure to ACEs is enough to trigger the child find mandate, then entire neighborhoods of children would need to undergo evaluations as part of a public-school enrollment process. The Compton and Havasupai litigants argue that Section 504's child find obligation requires precisely that - evaluations to determine whether children in crime ridden and impoverished communities need special education or related services. But while the science around ACEs points to a broader understanding of what may be a qualifying disability, Section 504's child find obligation contains some limiting principles.

First, Section 504 does not task schools with finding all students who may have a disability, but rather only those students who may have a disability that requires special education or related services in order to ensure FAPE. ${ }^{224}$ The root of Section 504's FAPE mandate is to ensure equality of educational access. ${ }^{225}$ Schools must identify students with disabilities so that they can ensure educational access that is equal to their peers. For example, a student with a hearing impairment who is able to understand one hundred percent of what is being said through the use of a hearing aid does not require special education or related services. Thus, even though the student with a hearing impairment would be protected by Section 504 and the ADA's anti-discrimination provisions, the school has no duty to find or evaluate the child because they require no special education or related services. ${ }^{226}$

223. The Compton plaintiffs were not arguing that "complex trauma" should be recognized as a new category of disability, but rather that exposure to traumatic events chronically impacts students regardless of whether an underlying medically diagnosable disability is found. P.P. Complaint, supra note 9; ๆๆ 1-13; Stephen C. Complaint, supra note 9, ๆๆ 310-316.

224. 34 C.F.R. § 104.35; see also PARENT \& EDUCATOR RESOURCE GUIDE, supra note 162.

225. 34 C.F.R. $\S 104.33$.

226. Attending Public Elementary, supra note 125, at Q11. 
Second, while a "qualified individual with a disability" may be interpreted broadly, schools are limited in their obligation to those students by the definition of FAPE. Section 504's FAPE standard is defined comparatively - schools must design educational programs to meet the individual educational needs of qualified students with disabilities as adequately as their nondisabled peers. ${ }^{227} \mathrm{~A}$ need for "special education" may be triggered when a student needs something different than what is offered to all other students in order to have equal access to the curriculum. The same is true for "related services"-supportive services needed for equal access to the curriculum. In its guidance on Section 504, the Department of Education states that academic struggles are not the only signal of a need for special education or related services. Rather, behavioral struggles, communication inhibitors, or anything preventing a child from accessing curriculum as equally as nondisabled peers may signal a need to evaluate for Section 504 eligibility. ${ }^{228}$

Consequently, while schools are obligated to identify students with eligible disabilities, Section 504 only mandates they engage in that task with an eye towards students who require something extra (special education or related services) to access their education as effectively as their non-disabled peers. ${ }^{229}$ Importantly, it does not ask that schools optimize a child's educational experience or ensure a particular outcome, but only that it provide equal access to education. ${ }^{230}$ Arguably, for children living in violent and impoverished neighborhoods, the stress of life in this environment alone would not signal a need to evaluate them under Section 504. Rather, students must demonstrate the inability to grasp academic content or conform behavior to school-based norms as effectively as one's peers.

That being said, the science linking ACEs to a heightened response to stress and perceived threats may lower the threshold for when schools are sufficiently on notice of a suspected disability. For instance, a school operating in a community where high incidences of ACEs are probable may be on notice of a child with a disability when a student often violates school

227. 34 C.F.R. $\S 104.33$.

228. 42 U.S.C. $§ 12102$ (2012); 154 CONG. REC. S8342, S8344 (daily ed. Sept. 11, 2008) (statement of the Managers to Accompany S. 3406, The Americans with Disabilities Act Amendments Act of 2008); see also Attending Public Elementary, supra note 125125, at Q7 \& Q9.

229. 34 C.F.R. $\S \S 104.35,104.33$.

230. 34 C.F.R. § 104.33; Lyons v. Smith, 829 F. Supp. 414, 420 (D.D.C. 1993) ("Therefore, in some situations, a school system may have to provide special education to a handicapped individual in order to meet the educational needs of a handicapped student 'as adequately as the needs' of a nonhandicapped student, as required by $\S 104.33$ (b)(1). Provision of special education under this regulation, however, would exceed the scope of aid authorized by the Rehabilitation Act if this relief called for accommodations beyond those necessary to eliminate discrimination."). 
rules or seems unable to conform behavior to acceptable norms. Whereas a student without known exposures to ACEs who is often disciplined may not trigger the child find obligation. Thus, an adequate understanding of ACEs may prompt earlier referrals for suspicion of disability in children who exhibit problematic behaviors. ${ }^{231}$ But even school districts with knowledge of this science may not necessarily run afoul of Section 504's child find requirements until students begin demonstrating academic or behavioral struggles. Essentially, child find is not triggered by exposure to ACEs alone, but rather still requires reasonable suspicion of a disability requiring special education or related services. ${ }^{232}$

Ultimately, child find's reasonable suspicion standard places considerable onus on teachers who serve on the front-lines of the identification process. While teachers are not meant to be experts in disabilities, by virtue of their daily classroom experiences, they acquire specialized knowledge about typical child development. It is this knowledge that allows them to spot variances from the norm. Once they are aware of a variance, it is their job, with the help of parents and other school members, to attempt to figure out the root cause of the child's struggle as well as identify potential interventions. At a certain point, it is also a teacher's responsibility to recognize that specialized assistance may be necessary and refer a child for an evaluation to uncover the root of a child's challenges. Schools that have weak referral systems or schools that neglect to regularly intervene with struggling students may violate child find. But the trigger for the evaluation is not knowledge of the disability itself, rather it is the child's academic or behavioral struggles. ${ }^{233}$

Behavioral struggles will be apparent whether the child is eventually diagnosed with an anxiety disorder, PTSD, or is suffering from the effects of ACEs. What may have changed is a school's need to evaluate for a disability upon any sign of behavioral challenges in a population of students with probable exposure to ACEs. Rather than assume the behavior is simply the child's unwillingness to follow the rules, science may dictate that the appropriate assumption should be to explore exposure to ACEs and any resulting impacts. The trouble with such an assumption, even though based in the science of ACEs, is that it has the potential to stigmatize poor communities of color. ${ }^{234}$ This unintended, but potentially dangerous consequence, will be explored more fully in section III.D.

231. See supra section I.A.2.

232. See supra section I.A.2.

233. See supra section I.A.2.

234. See infra section III.D. 


\section{B. The Limits of Free Appropriate Public Education (FAPE)}

While it may be true that many students exposed to ACEs require additional supports to meaningfully access education, it is certain that not all do. Not all children impacted by ACEs will respond in the same way. Not all will need interventions, and those that do will not all need the same interventions. Disability rights laws demand that schools find out which students actually require additional supports and provide targeted services to meet individual needs. ${ }^{235}$ Thus, once a child meets the definition of an "individual with a disability" under either Section 504 or the ADA, the inquiry shifts to what affirmative actions must schools take in order to ensure equal educational opportunities. ${ }^{236}$ This question is answered by the FAPE regulation.

\section{Clarifying Section 504's FAPE Obligation}

All elementary and secondary school students who qualify under Section 504 and the ADA are entitled to FAPE, defined as "the provision of regular or special education and related aids and services that [] are designed to meet individual educational needs of [students with disabilities] as adequately as the needs of [nondisabled students]." ${ }^{237}$ Notably, not all students with disabilities will need supports or services, but they are all still protected by the laws' broader anti-discrimination mandates. ${ }^{238}$ Courts and agencies interpret FAPE's limitations differently, but both agree that the FAPE regulation requires a targeted approach directed at an individual student's needs.

235. 34 C.F.R. $\S \S 104.32,104.35$.

236. Americans with Disabilities Act of 2008, Pub. L. No. 110-325, § 2(b)(2)-(5), 122 Stat. 3553, 3554 (2008) (codified at 42 U.S.C. $\S 1232$ (2012)) (“ADA”); Id. $\S \S 104.4,104.34 ; 28$ C.F.R. $\S 35.130(\mathrm{~b})(7)$ (2019); see also Weber, supra note 3535, at 24.

237. Section 504 obligates schools to "provide a free appropriate public education to each qualified handicapped person" who resides in the school district. 34 C.F.R. $\S 104.33$ (b)(1) (2019). While the ADA does not specifically address the provision of FAPE, OCR has noted that a district's obligations under Section 504 and the ADA "are generally the same." Nick J. Rahall, House of Representatives, Washington, D.C., 21 I.D.E.L.R. 575, at 1 (Office for Civil Rights, E. Div. of Philadelphia, June 22, 1994) (on file with author). As such, a district must provide FAPE to students with disabilities to comply with the ADA. Id.; see also Naco (AZ) Elem. Sch. Dist. No. 23, 107 L.R.P. 39965 (Office for Civil Rights, W.D., Az., Oct. 2, 2006); Issaquah (WA) Sch. Dist. No. 411, 40 I.D.E.L.R. 53 (Office for Civil Rights, W. Div., Wash. May 2, 2003); Pleasant Valley (CA) Elementary Sch. Dist., 32 I.D.E.L.R. 6 (Office for Civil Rights, W. Div., Cal., June 29, 1999).

238. Individuals covered by Section 504 or the ADA are also protected from discrimination, retaliation and harassment, regardless of whether or not they need special education or related services. 34 C.F.R. $\S 104.4$, 104.21-104.23, 104.61; 28 C.F.R. $\S 35$. 
Agency's interpretation of the FAPE regulation suggests schools must provide whatever supports are necessary to eliminate discrimination. ${ }^{239}$ OCR points to the plain language of the regulation as guidance of Congress's intent to make elementary and postsecondary schools accountable for meeting the educational needs of their students equally. ${ }^{240}$ Consequently, OCR instructs that financial considerations should not factor in the FAPE analysis. ${ }^{241}$ Rather, the only consideration should be whether or not the educational support or related service is necessary to eliminate discrimination. ${ }^{242}$ Under this reading, substantial adjustments may be required to meet the needs of students with disabilities as adequately as their peers. ${ }^{243}$

Courts, however, have interpreted the FAPE obligation to mean that "a school district must reasonably accommodate the needs of the handicapped child so as to ensure meaningful participation in educational activities and meaningful access to educational benefits." ${ }^{244}$ The "reasonable accommodations" language is borrowed from the ADA's implementing regulations which state a public entity must "make reasonable modifications in policies, practices, or procedures when the modifications are necessary to avoid discrimination on the basis of disability." ${ }^{245}$ An exception to this mandate applies where the public entity can demonstrate that making the modifications would "fundamentally alter the nature of the services, program, or activity." ${ }^{246}$ Clearly, the ADA regulation places limits on schools' obligations, instructing that schools must only provide that which is reasonable and setting aside "fundamental

239. 34 C.F.R. $\S 104.33(a)-(d)$.

240. Letter to Perry A. Zirkel, 20 I.D.E.L.R. 134 (Office of Civil Rights, U.S. Dep't of Educ., Aug. 23, 1993).

241. Id.

242. Id. at 2 ("If a school district is meeting the needs of children without disabilities to a greater extent than it is meeting the needs of children with disabilities, discrimination is occurring.").

243. Id.

244. Blunt v. Lower Merion Sch. Dist., 767 F.3d 247, 274 (3d Cir. 2014) ("However, $\S 504$ does not mandate 'substantial' changes to the school's programs, and courts 'should be mindful of the need to strike a balance between the rights of the student and [his or her] parents and the legitimate financial and administrative concerns of the $[\mathrm{s}]$ chool $[\mathrm{d}]$ istrict ... mere administrative or fiscal convenience does not constitute a sufficient justification for providing separate or different services to a handicapped child." (citing Ridley Sch. Dist. v. M.R., 680 F.3d 260, 280-81 (3d Cir. 2012))).

245. 28 C.F.R. $\S 35.130($ b)(7) (2019).

246. 28 C.F.R. $\$ 35.130($ b)(7); Rothschild v. Grottenthaler, 907 F.2d 286, 293 (2d Cir. 1990). Confusion about the reasonable accommodation limitation may also stem from separate subparts of Section 504, which do contain such language. For instance, part B which covers employers contains a reasonable accommodations limit and part $\mathrm{E}$, which covers postsecondary schools, states when a recipient can demonstrate that an academic requirement is essential to the program of instruction a failure to modify will not be regarded as discriminatory. 34 C.F.R. $\S \S 104.12$, 104.44 (2019). 
alterations" as unreasonable and thus, unwarranted. By reading "reasonableness" into the FAPE standard, courts put limits on schools' obligations to confer FAPE that are not contained in the plain language of the regulation. ${ }^{247}$

While both the FAPE regulation and the ADA's reasonable accommodations regulations apply to public schools, the ADA's regulation should not be read as imposing limits onto FAPE. ${ }^{248}$ Rather, the FAPE standard is limited by what is needed to ensure equality. Importantly, nothing in either law demands that schools provide "potential-maximizing education," but rather both task schools with providing supports and services that give students with disabilities "the same access to benefits as all other public education students." 249 Essentially, Section 504 and the ADA do not require schools to develop flawless or even optimal educational programs; rather, both laws suggest that a reasonable plan designed to meet the needs of students with disabilities as adequately as their non-disabled peers would suffice. ${ }^{250}$

Because courts often impose a reasonable accommodations analysis to claims brought under Section 504 and the ADA, the following section will discuss ACE claims within the context of both FAPE and reasonable accommodations. It illustrates how, in either context, class-based remedies for system-wide programmatic changes stretch the contours of those obligations.

\section{The Impossibility of Class-Based Remedies for Programmatic Change}

Quite clearly, both laws put limits on how far schools must go in their provision of disability supports. ${ }^{251}$ Schools only need to provide those supports necessary to eliminate discrimination. Within the context of education, this is defined as offering students FAPE. FAPE, in turn, is rooted in a school district's obligation to an individual student. Class-

\section{Blunt, 767 F.3d at 274.}

248. 28 C.F.R. $§ 35.103$ (a) ("Rule of interpretation. Except as otherwise provided in this part, this part shall not be construed to apply a lesser standard than the standards applied under title $\mathrm{V}$ of the Rehabilitation Act of 1973 (29 U.S.C. 791 (2012)) or the regulations issued by Federal agencies pursuant to that title.”); see also 28 C.F.R. § 130(b)(7) (Comments by Dep't of Justice); 28 C.F.R. ch. 1, pt. 35, app. B, at 673 ("[T]he House Judiciary Committee Report directs the Attorney General to include those specific requirements in the Title II regulation the extent they do not conflict with the regulations implementing section 504.").

249. J.D. ex rel. J.D. v. Pawlet Sch. Dist., 224 F.3d 60, 71 (2d Cir. 2000).

250. K.K. ex rel. L.K. v. Pittsburgh Pub. Schs., 590 F. App'x 148, 153-54 (3d Cir. 2014); 34 C.F.R. $\S 104.33$.

251. 28 C.F.R. $\S 35.164$. 
based litigation stretches the contours of this obligation by forcing FAPE to into a group-based remedy, something the language of the law clearly does not contemplate. For a class of plaintiffs to prevail on a claim of systemwide accommodations under Section 504 or the ADA, they would need to show that such accommodations are required to eliminate discrimination. In other words, the system-wide remedy is necessary to meet their needs as adequately as those of their non-disabled peers.

Because the heart of a systemic claim for services under Section 504 is situated in a denial of FAPE, the remedy sought (systemic) conflicts with the nature of Section 504's FAPE obligation (individualized). Section 504 defines FAPE individually: the statute directs schools to design regular or special education services to meet the "individual educational needs" of students with disabilities as adequately as those without. ${ }^{252}$ It further mandates that schools conduct individual evaluations of each child suspected of needing special education or related services in order to assess individual needs and as a precursor to designing an appropriate plan. ${ }^{253}$ By its very definition, the FAPE obligation must be individually tailored to each child. While a group of children may be denied FAPE, the remedy must be individual in nature because the very definition of FAPE is tied to an individual child. ${ }^{254}$ The law clearly disfavors a one-size-fitsall approach. Rather than a system wide remedy to address FAPE, Section 504 requires an individualized education program suitable to a particular child's disability-based needs.

Because Section 504 requires schools to ensure meaningful access through FAPE and FAPE is, in turn, an individualized comparative standard, schools arguably cannot fulfill this obligation with a collective systemic remedy. Rather, schools must fulfill this obligation to each individual child. Thus, while a school may have denied FAPE to a class of students by failing to conduct evaluations and design effective education programs, this failure cannot be remedied by a one-size-fits-all school-wide reform. Rather, the remedy called for by Section 504's FAPE regulation would be to ensure individual evaluations of each child suspected of having a disability and to ensure the development of accommodations, including special education where needed, to guarantee equality within the educational program.

While Section 504 may support systemic remedies that relate to process including, effective procedural safeguards and comprehensive evaluations, such systemic remedies are not appropriate when the substance of the educational program is at issue. The ineffectiveness of

252. 34 C.F.R. $\S 104.33$.

253. Id. $\S 104.35$.

254. Id. $\S 104.33$. 
system-wide substantive remedies is illustrated through a simple hypothetical. Assume that rather than ACEs, a school district served a neighborhood of children with varying levels of vision impairment-a more objectively measurable disability. Once the school is aware that some percentage of its students are visually impaired, the appropriate response is not to offer every child the same prescription of glasses, make the font larger in all textbooks, or offer guide dogs to all children. Of course, put in this context, such broad and systemic responses sound absurd. Quite obviously, the appropriate response is to screen each child to determine the degree of impairment for that child and provide individualized supports or services. Similarly, system-wide accommodations meant to address the varied impacts of ACEs are just as ill-suited to the task. Rather, in both scenarios, the logical first step is an individualized determination of the disability's effects on a particular child - not system-wide accommodations.

Were courts to apply a reasonable accommodations analysis, a claim for system-wide programmatic changes would still fall flat. Schools could claim such remedies amount to a fundamental alteration to the nature of the school's program. Indeed, several courts have signaled a deference towards schools when accommodations cause financial or administrative burdens on school systems. ${ }^{255}$ Not all, but many program-wide changes could trigger issues of both cost and administration. Further, the very nature of a systemic remedy is to change the structure of the status quo, which may be required to avoid discrimination at least in some cases. ${ }^{256}$ For instance, the Compton Plaintiffs' Section 504 claim centered on three district-wide remedies: (1) training teachers to recognize effects of complex trauma and teach students self-regulation and social-emotional skills; (2) developing restorative justice practices; and (3) ensuring school-wide mental health supports. ${ }^{257}$ Given what programmatic structures are currently available in Compton schools, it is easy to see how the school district could successfully argue that such structural changes represent a fundamental and costly change to existing school programs.

Determining whether school-wide modification rises to the level of an unreasonable or "fundamental or substantial modification of its program or standards" will depend on a district's current programmatic

255. J.D. ex rel. J.D. v. Pawlet Sch. Dist., 224 F.3d 60, 70-71 (2d Cir. 2000); Rothschild v. Grottenthaler, 907 F.2d 286, 293 (2d Cir. 1990).

256. Alexander v. Choate, 469 U.S. 287, 300 (1985).

257. Compton plaintiffs proffered expert testimony alleging that school-wide interventions were the only effective way to ensure students with complex trauma would not be denied meaningful access. P.P. Complaint, supra note 9, at 61 . 
offerings. ${ }^{258}$ Demands that schools change curricular content for all students based on the needs of some may be met with fierce resistance from schools. Further, such requests are likely to face significant challenges with courts known for their deference to school officials around matters of educational policy. ${ }^{259}$ In essence, such demands make an end run around the traditional educational decision-makers and ask courts to effectuate changes to educational policies. Courts will likely be exceedingly leery of doing so when such changes not only impact all students, but also seem to be of the type traditionally left in the realm of school officials and elected school board members.

For instance, the Compton litigants demanded new curriculum (social emotional learning and self-regulation skills) be taught to all students as a system-wide accommodation. ${ }^{260}$ Yet, this type of remedy is the type of educational policy decision courts have historically been the most uncomfortable making. ${ }^{261}$ Indeed, by mandating this change, courts permit disability rights laws to dictate curricular content for all students, potentially altering a school's pedagogical approach to education. On the other hand, if school districts have already begun to incorporate such practices, courts may not balk at ordering improvements in existing programs as such action would not equate to a fundamental change. ${ }^{262}$

While disability rights laws may provide protections for students impacted by ACEs, class-action lawsuits that seek systemic remedies based on a theory that disability is more prevalent in certain neighborhoods fail to recognize the limits of the laws they invoke. Both the ADA and Section 504 require schools to provide meaningful access to education, but this obligation is inextricably linked to a student's ability to gain access to statutory protections establishing their status as a "qualified individual with a disability" and their disability-based needs. ${ }^{263}$

Fundamentally, these lawsuits skip the important steps of identifying who those children are and accounting for the individualized impacts of their disabilities before demanding appropriate relief. Quite clearly, not every child exposed to a traumatic experience will respond in the same way. Thus, even if children in the same neighborhood are all exposed to community violence (a recognized adverse childhood experience), their

258. Zukle v. Regents of Univ. of Cal., 166 F.3d 1041, 1047 (9th Cir. 1999).

259. Endrew F. ex rel. Joseph F. v. Douglas Cty. Sch. Dist. RE-1, 580 U.S. _, 137 S. Ct. 988 , 1001 (2017); Bd. of Educ. v. Rowley, 458 U.S. 176, 207-08 (1982).

260. P.P. Complaint, supra note 9, ๆ 6.

261. Endrew, 137 S. Ct. at 1001; Rowley, 458 U.S. at 207-08.

262. K.N. v. Gloucester City Bd. of Educ., 379 F. Supp. 3d 334, 355 (D.N.J. 2019) (finding that a requested accommodation could not be a fundamental alteration to a school's program where the plaintiff had previously received the accommodation).

263. 29 U.S.C. $\S 794$ (2012). 
reactions to that exposure will vary. The supports, accommodations, or other educational services they may need as a result of this adversity may vary as well. Essentially, these parties ask courts to assume that all students who have experienced trauma require the same set of accommodations in order to meaningfully access education. The science supporting effects of ACEs on brain development is both reliable and compelling, but even accepting the research as valid, it fails to sufficiently inform courts about the impact on any individual child. And when the laws' substantive protections are bound to the individual child's needs, such class-based suits seek an impossible remedy.

\section{Additional Legal Hurdles}

Beyond the limitations tied to the FAPE and reasonable accommodations regulations, several additional hurdles stand in the way of successfully leveraging disability laws as agents of educational reform. While all can likely be overcome, they are worth briefly noting as they help present a clearer picture of the challenges placed on class-based relief.

The first obstacle arises from IDEA's exhaustion clause. ${ }^{264}$ The IDEA requires that plaintiffs who seek relief available under the IDEA must exhaust administrative remedies before bringing suit under any other law, including the ADA and Section 504. ${ }^{265}$ The only exception is when the remedy sought is not centered on a denial of IDEA's FAPE requirements. ${ }^{266}$ Whether an exception also exists for denials of FAPE under Section 504 is unclear. ${ }^{267}$ Thus, plaintiffs bringing a Section 504 FAPE claim may need to convince a court that the IDEA's exhaustion clause does not apply due to the distinctions in FAPE obligations under each law. Should that argument fail, plaintiffs may still prevail under one of the exceptions to administrative exhaustion - most likely by claiming that the remedy sought is a systemic change incapable of individual relief. ${ }^{268}$

264. 20 U.S.C. $\S 1415(l)(2012)$.

265. Id.

266. Fry v. Napoleon Cmty. Schs., 580 U.S. _, 137 S. Ct. 743, 746 (2017) (holding IDEA exhaustion not required when the remedy sought is not for the denial of a free appropriate public education (FAPE)).

To determine whether a plaintiff in a suit brought under a statute other than the [IDEA] seeks relief for the denial of a free appropriate public education (FAPE), such that the plaintiff is required to exhaust IDEA's remedies, a court should look to the crux, or the gravamen, of the plaintiff's complaint, setting aside any attempts at artful pleading.

Id. at 743 .

267. Id. at 747 .

268. D.R. v. Mich. Dep’t of Educ., No. 16-13694, 2017 WL 4348818, at *3 (E.D. Mich. Sept. 29, 2017). 
The second obstacle to class-based relief centers on the exceedingly murky court interpretations of the intent standard required for Section 504 and ADA claims. Many circuits have held that when plaintiffs seek nonmonetary remedies, such as the declaratory and injunctive relief sought in ACEs-based class actions, they need not prove intentional discrimination. ${ }^{269}$ In these circuits, plaintiffs need only prove discriminatory effects resulting from their status as an individual with a disability. ${ }^{270}$ However, a few circuits require plaintiffs to prove an "aggravated denial of reasonable accommodation," which means a showing of bad faith or gross departure from professional judgment in all Section 504 and ADA claims. ${ }^{271}$ While many scholars have criticized this heightened standard, ${ }^{272}$ several circuits continue to insist on it in claims alleging non-intentional discrimination. ${ }^{273}$ Consequently, plaintiffs seeking class-based relief, even when alleging non-intentional harms, may need to prove the school districts' policies or practices amounted to a gross departure from professional judgement. ${ }^{274}$

Finally, to successfully allege that a school district failed to implement a regulation, plaintiffs must first demonstrate that the cited regulation is privately enforceable. As a general principle, regulations are only privately enforceable if their requirements fall within the scope of the prohibition contained within the statute. ${ }^{275}$ The Supreme Court has long-

269. Mark C. Weber, Accidentally on Purpose: Intent in Disability Discrimination Law, 56 B.C. L. REV. 1417, 1433 (2015).

270. Perry Zirkel, Do Courts Require a Heightened, Intent Standard for Students' Section 504 and ADA Claims Against School Districts? 47 J.L. \& EDUC. 109 (2018) (charting differences in courts' approaches to requiring intent in disability discrimination cases brought under Section 504 and Title II of the ADA).

271. Weber, supra note 269, at 1456 (identifying courts that impose a higher standard when analyzing claims for reasonable accommodations brought by students in schools); see also D.R., 2017 WL 4348818, at *9 (holding that while "a mere disagreement in FAPE is not sufficient to show discrimination," plaintiffs' allegation that school district's professional judgment in oversight of its programs, and the allocation of necessary resources have caused discriminatory effects may rise to the level of bad faith or gross departure from professional judgment).

272. Weber, supra note 269, at 1417; see also Zirkel, supra note 270, at 109.

273. Monahan v. Nebraska, 687 F.2d 1164, 1170 (8th Cir. 1982); see Weber, supra note 269, at 1433.

274. See Weber, supra note 269 , at 1456 . These ACEs based class-action lawsuits have thus far proceeded under theories of nonintentional discrimination and have sought non-monetary relief. Plaintiffs allege a failure to identify students with disabilities and failure to provide reasonable accommodations. Neither of these claims allege that schools intended to harm or discriminate against students with disabilities, but rather that the effect of the school's actions or inactions resulted in a denial of meaningful access to education for students impacted by ACEs. To remedy this discrimination, plaintiffs demanded declaratory or injunctive relief. See supra section I.C.

275. Alexander v. Sandoval, 532 U.S. 275, 288-89 (2001). The Supreme Court has interpreted this to mean that regulations can only be enforced through the private right of action contained in a statute when they "authoritatively construe" the statute; regulations that go beyond a construction of the 
held that Section 504 itself establishes an implied private right of action allowing victims of prohibited discrimination, exclusion, or denial of benefits to seek "the full panoply of remedies, including equitable relief and compensatory damages." ${ }^{276}$ Lawsuits proceeding under a theory of ACEs as disability invoke Section 504's FAPE and child find regulations and, thus, must demonstrate that each regulation is privately enforceable. ${ }^{277}$ Recent court opinions suggest they will likely succeed in both. ${ }^{278}$

\section{The Societal Cost}

There is no question that students impacted by poverty, community violence, instability, and other ACEs face significant challenges when it comes to overcoming the impacts of such disadvantage. ${ }^{279}$ But, classaction suits seeking systemic services for students exposed to ACEs essentially claim that all students in poor, minority neighborhoods are disabled and require something different in order to meaningfully access educational opportunities. As several scholars have illustrated, painting with such a broad brush risks further pathologizing predominately poor and minority communities as dysfunctional and damaged ${ }^{280}$ Historically, false and damaging beliefs about race and poverty have resulted in policies that stigmatize African-Americans and disproportionately oppress low-income communities of color. ${ }^{281} \mathrm{~A}$ second problem with such suits is they incentivize a broad remedy which may be effective for some, but not all students, at the expense of a remedy tailored to meet individual student needs.

statute's prohibitions do not fall within the implied private right of action, even if those regulations are valid. $I d$. at 284 .

276. Greater L.A. Council on Deafness, Inc. v. Zolin, 812 F.2d 1103, 1107 (9th Cir. 1987).

277. The Havasupai case filed claims for violations of location and notification, procedural safeguards, and FAPE. Second Amended Complaint for Declaratory and Injunctive Relief at 50-62, Stephen C. v. Bureau of Indian Educ., No. 3:17-cv-08004-SPL, 2018 WL 1871457 (D. Ariz. Mar. 29, 2018).

278. Mark H. v. Lemahieu, 513 F.3d 922 (9th Cir. 2008); Stephen C., 2018 WL 1871457, at*7.

279. Burke et al., supra note 44, at 412-13.

280. Nancy E. Dowd, Straight Out of Compton: Developmental Equality and a Critique of the Compton School Litigation, 45 CAP. U. L. REV. 199 (2017); Troutt, supra note 63, at 653-55 (cautioning that policies meant to treat widespread psychological trauma could further cement the narrative that already exists associated poor black families with dysfunction).

281. Troutt, supra note 63, at 653-55 (comparing the well-intentioned objective of systemic trauma interventions to the current system of child welfare laws and noting that, while child welfare laws were established for the protection of vulnerable children, "child welfare administration has given rise to consistent costs that fall disproportionately on the black poor . . . the costs include the stigma of being considered presumptively dysfunctional people"). 
Consequently, the fight for access to disability rights protections for this particular group of students comes with significant risks. If children from poor communities are understood to be somehow broken or dysfunctional, in large part, because of their relationship to that community, we risk perpetuating invidious racial stereotypes leading school systems and educators to buy into a false narrative that all students from these communities are damaged. Time and again, research shows that teacher expectations of their students matter. ${ }^{282}$ And sadly, many teachers lower their academic expectations when students carry the label of requiring "special education." 283 While the same fate may not hold true for students who seek accommodations for effects of ACEs, there is little reason to think otherwise. The label of "trauma" or "complex trauma" will likely begin to cloak children or entire schools in assumptions about capability, resilience, and frailty. In some instances, such assumptions will not work at crosspurposes and children will be able to achieve academic and emotional successes. But rest assured, there will also be times when teachers demand less of students with ACEs or assume they are capable of less because of the label itself. Of course, this result is inapposite to the very purpose for which disability rights laws were enacted.

A second risk in requesting a system-wide response is inviting schools to implement broad remedies without looking more closely at the needs of individual students. In short, it fits all children from certain communities into one box without regard to their individual needs or capabilities. Some schools may quickly assume, by virtue of their student demographic, that a majority of their students suffer the impacts of ACEs and institute systemic accommodations. Such action will likely be overinclusive and risks prioritizing the collective response over individual needs. Other schools, again simply by virtue of student demographics, may assume that only a tiny percentage of their students have suffered the effects of trauma and may fail to attribute academic or social challenges to a potential unidentified disability that requires special education or accommodations. In either scenario certain students are not served according to their individual needs.

Finally, such litigation effectively transforms disability rights laws into agents of educational reform and bypasses the legislative and democratic

282. Nicholas W. Papageorge, et al., Teacher Expectations Matter, I.Z.A. DiscussiON PAPER No. 10165 (2016) (DE), available at http://ftp.iza.org/dp10165.pdf [https://perma.cc/X9LW-N2MK] (demonstrating evidence that teacher expectations affect students' educational attainment and suggesting teacher expectations differ by racial groups in ways that disadvantage black students).

283. Claire Raj, The Misidentification of Children with Disabilities: A Harm with No Foul, 48 ARIZ. ST. L.J. 373 (2016) (discussing the stigma associated with being a child with a disability including lowering of expectations for academic success from teachers as well as from students themselves). 
systems currently in place to address education policy. Disability rights laws were enacted to ensure equal access to education which certainly includes the mandate to modify curriculum for an individual student where necessary to ensure meaningful access. ${ }^{284}$ Much less certain, however, is whether such laws can mandate curricular changes for an entire school. Education curriculum is normally dictated by the state, which typically designates such responsibility to local elected or appointed school boards. ${ }^{285}$ In this way, decisions about education policy and curriculum are at least in theory grounded in a democratic process. ${ }^{286}$ Allowing disability laws to influence such decisions marks a seismic shift in the way these decisions are typically made in that it removes them from the democratic process. Certainly, history reveals that at times court intervention is necessary to force states to make necessary changes to educational policy. ${ }^{287}$ State legislatures currently underfunding public schools and failing to adequately educate students may need the pressure of litigation to force their hand. ${ }^{288}$ The point here is simply that disability laws were not enacted for this purpose, and careful consideration should be given to whether they should and can be used to bring about such broad-based changes.

Notwithstanding the above concerns, disability law may have a central role to play in tackling the pervasive challenge ACEs present. The following Part will tackle two potential solutions to address the impacts of ACEs recognizing the limits of disability law and attempting to guard against over-identification of students as disabled.

\section{SOLUTIONS}

Using Section 504 or the ADA as a class-based remedy to provide systemic changes in schools presents the proverbial problem of trying to fit a square peg in a round hole. The statutes simply do not have the capacity to allow for such a remedy. Essentially, litigants are seeking a systemic change to the educational program based on two assumptions. First, that there are students with as-yet unidentified disabilities in the school district, and second, that these students require school-wide programmatic changes in order to meaningfully access education. While

284. See supra section I.B.

285. See generally SARAh M. Stitzlein, American Public Education AND the Responsibility of Its Citizens: Supporting Democracy in the Age of ACCOUntability (2017).

286. Id.

287. Constance Baker Motley, The Historical Setting of Brown and Its Impact on the Supreme Court's Decision, 61 FordHAM L. REV. 9 (1992).

288. John Dayton \& Anne Dupre, School Funding Litigation: Who's Winning the War?, 57 VAND. L. REV. 2351, 2354 (2004). 
the research supporting ACEs may make those assumptions more likely than not for a large percentage of students, Section 504 and the ADA demand individualized determinations of disability that require special education or related services. The laws do not leave room for assumptions or probabilities.

Moreover, class actions based on a theory of ACEs as a disability bring to light a tension between the harms of labeling entire communities of children as "disabled" by virtue of their membership in these very communities and the science that supports the idea that many, but not all, of these children suffer real emotional and physiological impacts because of their membership in this group. Attempting system-wide remedies for the whole group based on aggregate demographics of the group raises a problem that statistics literature refers to as the "ecological fallacy." 289 This principle states it is statistically incorrect to assume that one person in a group resembles the average or typical traits of the group. ${ }^{290}$ In the context of the Compton class-action suit, selecting one student at random in the Compton school district does not provide any statistical confidence that the child will be any more likely than anyone else in Compton to be impacted by ACEs and require supportive services to access education. Thus, broad-based reforms run the risk of being overinclusive. Disability rights law currently guards against ecological fallacy by requiring individualized decisions based on each child's unique needs. ${ }^{291}$

Addressing a community's need for services while guarding against the harms of overinclusion can be accomplished, but doing so requires both litigation and legislative strategies. The following section proposes two potential solutions that attempt to address both over-inclusion and a need for community-wide services. The first involves systematically litigating child find claims on behalf of students who clearly evidence impacts of ACEs with the goal of pressuring schools to adopt more efficient screening tools for ACEs. The second solution requires legislative action in the form of grant funding to support schoolwide trauma-informed services directed at schools that educate a significant percentage of students impacted by ACEs.

\section{A. Turning Individual Rights into Systemic Solutions}

Science reveals a tension between effectively meeting the needs of students impacted by ACEs and the limits of schools' obligations under

289. EnCyClopedia OF Survey ReSEArCh Methods 218 (Paul J. Lavrakas ed., 2008).

290. David Lubinski \& Lloyd G. Humphreys, Seeing the Forest from the Trees: When Predicting the Behavior or Status of Groups, Correlate Means, 2 PSYCHOL., PUB. POL'Y \& LAW 363, 375 (1996).

291. See supra section I.B. 
disability rights laws. Advocates want early identification of these students and schoolwide supports for what they believe to be a widespread problem. But, disability rights laws only require schools to act upon reasonable suspicion of a disability that requires supports and call for individualized, not group, interventions. ${ }^{292}$ In order to bridge this gap between what the law requires and the research supporting ACEs' widespread impacts, advocates should focus on bringing a series of individual child find claims on behalf of those students impacted by ACEs who clearly demonstrate learning or behavioral struggles. By bringing a series of these claims, advocates force schools to meet the needs of individual students and begin laying the groundwork to evidence the pervasiveness of ACEs. Ultimately, when faced with the reality of mounting child find claims, schools will be more likely to adopt universal screening tools and implement systemic reforms, even when not legally required, in order to more efficiently address the extensive impacts of ACEs.

Adopting this targeted approach could accomplish three important goals. First, it can pressure schools to voluntarily implement universal screening for ACEs-related impacts in order to provide supports to students who need them. Second, it would facilitate a more precise delivery of services that match individual student needs. Finally, once schools become aware of the breadth of ACEs within their student bodies, they may choose to implement schoolwide trauma-informed practices as a means of remedying widespread effects of ACEs, while still ensuring individualized services where needed.

The recent Flint, Michigan litigation to remediate the effects of lead exposure provides useful insights that support this Article's proposal. ${ }^{293}$ In 2016, a class of students in Flint, Michigan brought suit under the IDEA, Section 504, Title II of the ADA, and state laws on behalf of approximately 30,000 school-age children residing in Flint. ${ }^{294}$ The plaintiffs shared the unfortunate incidence of prolonged exposure to elevated levels of lead in the public water ${ }^{295}$ Lead exposure substantially increases the likelihood of cognitive-related disabilities. ${ }^{296}$ Thus, the representative plaintiff class claimed that as a result of this exposure, they

292. See supra sections III.A, III.B.

293. See D.R. v. Mich. Dep't of Educ., No. 16-13694, 2017 WL 4348818 (E.D. Mich. Sept. 29, 2017).

294. Id. at *1.

295. Class Action Complaint at 7, D.R., 2017 WL 4348818.

296. Mona Hanna-Attisha et al., Elevated Blood Lead Levels in Children Associated with the Flint Drinking Water Crisis: A Spatial Analysis of Risk and Public Health Response, 106 AM. J. PuB. HeAlth 283, 283 (2016); Bruce P. Lanphear et al., Low-Level Environmental Lead Exposure and Children's Intellectual Function: An International Pooled Analysis, 113 Envtl. HeAlth Persps. 894, 894 (2005). 
required "community-wide early screening; timely referral for, and performance of, evaluations to determine whether they have a qualifying disability which makes them eligible for special education and related services. ${ }^{2297}$ The plaintiffs invoked both the IDEA as well as Section 504 and Title II of the ADA, but the court's ruling on their substantive claims focused mainly on the IDEA. ${ }^{298}$ While the case was ultimately settled, the plaintiffs' claims survived a motion to dismiss. ${ }^{299}$ At that point, the plaintiffs were able reach a favorable settlement which dramatically improved child find procedures. The school district agreed to implement universal screening for potential impacts of lead exposure and facilitate comprehensive evaluations, including neuropsychological evaluations when needed..$^{300}$

The strategy in Flint to strengthen child find procedures offers an important path forward for students impacted by ACEs and suggests that improving identification processes, rather than demanding services, is the first step to reform. Lead exposure is clearly linked with disability, but exposure does not automatically equate to disability. As the Flint plaintiffs explained, exposure to lead may have significant detrimental impacts on learning or other cognitive and physiological impacts, but "it is impossible to predict in advance how lead will impact a specific individual." ${ }^{301}$ Notwithstanding these uncertainties, the plaintiffs succeeded because of the close nexus between exposure to lead and the eventual likelihood of a disability requiring special education. ${ }^{302}$ The school district believed it highly likely that many of Flint's lead exposed children would eventually meet IDEA's eligibility parameters. Once they did, these children would have a right to demand special education supports and services and could also bring claims alleging that the school district failed to identify them within a reasonable amount of time. The school district wisely chose to

297. Class Action Complaint at 7, D.R., No. 16-13694, (Oct. 18, 2016).

298. Id. at 1 .

299. D.R., 2017 WL 4348818 , at *1.

300. Preliminary Settlement Agreement at 4-7, D.R., 2017 WL 4348818 (Apr. 9, 2018) (No. 1613694), available at https://www.clearinghouse.net/chDocs/public/ED-MI-0007-0006.pdf [https://perma.cc/Z7SC-D28W].

301. Plaintiffs' Reply Brief in Support of Motion for Preliminary Injunction at 25, D.R., No. 1613694, (Nov. 17, 2017).

302. Michigan agreed to fund developmental screenings and comprehensive special education evaluations for thousands of children exposed to lead in public drinking water. The state will create a registry system where families can choose to enroll their children for the initial screening. Further assessments, including neuropsychological tests, will be conducted where needed. Settlement Agreement, D.R., 2017 WL 4348818 (Apr. 9, 2018) (No. 16-13594), available at http://dataserver.lrp.com/DATA/servlet/DataServlet?fname=D.R._v._Mich._Dept_of_Educ._Final_ Settlement_Agreement.pdf [https://perma.cc/Z7SC-D28W]. 
get out ahead of these claims by shoring up their identification process in order to both find the children suffering the impacts of lead exposure and design appropriate interventions and supports to meet their needs.

Significant differences exist between disability eligibility based on lead exposure as compared to ACEs. Lead poisoning is specifically listed as an example of an acute health problem that could meet the IDEA's OHI disability definition. ${ }^{303}$ ACEs are not. Moreover, the effects of exposure to lead as compared to ACEs differ dramatically. ${ }^{304}$ Yet, these differences do not preclude the viability of similar claims based on a theory of ACEs. ACEs can be likened to environmental "toxins" that, just like lead, have the potential to negatively impact learning. ${ }^{305}$ By virtue of exposure to ACEs alone, children increase their risk of negative health outcomes. ${ }^{306}$ Importantly, just like the lead-exposed children, it is impossible to predict in advance how ACEs will impact any individual child or even whether all children with ACEs will be adversely affected. Demanding that schools account for this reality by implementing effective ACEs screening tools ensures that those students who need services are provided them and helps guard against over-identification risks. Ensuring effective screening tools will also help schools gather additional helpful student-specific information to determine when more comprehensive evaluations might be required. ${ }^{307}$

Accounting for the differences between ACEs and lead, a successful ACEs litigation strategy must be grounded in the Section 504 child find obligation, given the law's broader eligibility parameters. ${ }^{308}$ Further,

303. 34 C.F.R. § 300.8(9)(i) (2019).

304. Lanphear et al., supra note 296, at 894; cf. Effects, supra note 63.

305. One significant difference between lead and ACEs is that no known antidote exists to lessen the impact of lead exposure for children. However, children may have varying levels of resiliency including stabilizing adult relationships, that can lessen the impact of exposure to ACEs. Treatment of Lead Poisoning, AM. ACAD. PEDIATRICS, https://www.aap.org/en-us/advocacy-and-policy/aaphealth-initiatives/lead-exposure/Pages/Treatment-of-Lead-Poisoning.aspx [https://perma.cc/ZJ98$95 \mathrm{VY}]$ (finding that the primary treatment for lead poisoning is eliminating the source of lead exposure).

306. See supra section I.A.

307. Universal screenings may help identify when a child should be referred for comprehensive evaluation under the IDEA or Section 504 and the ADA. 20 U.S.C. 1414 (a)-(c) (2018); 34 C.F.R. $\S 104.35$ (b). In some cases, the IDEA evaluation process may provide a school district with information necessary to determine eligibility under Section 504 and the ADA. PARENT \& EDUCATOR RESOURCE GUIDE, supra note 162, at 42. ACEs-related universal screening tools exist and can help distinguish which students require further interventions due to impacts of trauma. Complex Trauma Standardized Measures, NAT'L ChILD TRAumatic Stress NeTWork, https://www.nctsn.org/resources/complex-trauma-standardized-measures [https://perma.cc/2AFL4DES]; see also EKLUND \& ROSSEN, supra note 166 (discussing the benefits of implementing universal screenings as an essential component of multi-tiered systems of support).

308. See supra section II.B. Notably, lead poisoning, unlike ACEs, is explicitly listed under the IDEA's "other health impairment" disability category. 34 C.F.R. § 300.8(9)(i). 
because exposure to ACEs presents a more tenuous path to a potential need for educational supports, litigants would be better served by bringing a series of individual child find claims on behalf of children who clearly evidenced the impacts of ACEs as evidenced by learning or behavioral challenges. A series of successful claims would pressure a school district to adopt improved child find procedures, including universal screenings for ACEs related impacts. Just as in the Flint settlement, universal screenings may trigger more comprehensive evaluations when needed. ${ }^{309}$

Improved child find procedures, beginning with universal screenings, may uncover an overwhelming need for mental health counseling for a large swath of students in a school district such as Compton-with attendant incidents of poverty and community violence. If so, the final result of an improved screening and evaluation process in a school district serving a community of students with a high incidence of ACEs may be the same remedy that the Compton complaint demands. An individualized screening process that identifies some critical mass of students as requiring mental health services (as well as instruction targeted at building social emotional skills) would likely force a district to adopt schoolwide programmatic reforms. The difference between this Article's strategy and that of the Compton plaintiffs is that the school district would elect to provide those services based on administrative and fiscal efficiencies. They would rely on the data they begin to develop about their student population's collective needs, not just succumb to assumptions. They may also engage in the regular democratic process to make broader policy changes and by doing so, may solicit community feedback.

A potential avenue for a class-based child find remedy exists through the IDEA, but it only tangentially centers on ACEs. It would require a putative class to marshal statistical evidence of a school district's failure to identify students with disabilities as compared to other similarly situated districts. A class of former preschool-aged children successfully brought such a claim in the District of Columbia. ${ }^{310}$ There, plaintiffs successfully argued that the school district was failing to identify students with disabilities using national rates of special education enrollment and expert testimony regarding risk factors unique to District of Columbia. ${ }^{311}$ Such a claim is based on risks inherent to impoverished urban jurisdictions. ${ }^{312}$ Exposure to ACEs may be included as an additional risk

309. 34 C.F.R. $\S 104.35$.

310. D.L. v. District of Columbia, 860 F.3d 713 (D.C. Cir. 2017).

311. Id. at 720 .

312. Id. at 728. In D.L., the District court imposed an $8.5 \%$ identification benchmark finding that: although 'nationally, about six percent of three-to-five-year-olds are identified with developmental delays,' the number is likely higher in the District because of its unique risk 
facing children in such environments. The remedy here, like in the individual claims, is to shore up a school's child find procedure so that children who do need supports are provided them.

\section{B. $\quad$ Creating Federal Grants to Address System-Wide Supports}

A second solution involves congressional action in the form of federal and state grants targeting schoolwide needs brought on by serving a large population of students impacted by ACEs. Of course, this solution requires prevailing upon federal and state legislators to direct grant funding towards communities impacted by ACEs. Once funds were allocated, school districts could apply for grants upon a showing that their student population met a threshold percentage of ACEs-impacted students. Funding could be used to implement schoolwide training for teachers, mental health counseling, and other evidence-based interventions that have proven effective in addressing the impacts of ACEs.

The benefits of establishing such grants are clear and compelling. By requiring a threshold percentage of ACEs-impacted students, grants would incentivize school districts to establish solid procedures for the identification of students impacted by ACEs and to be proactive in their attempts to address this population's collective needs. Further, facilitating grants supports a grassroots approach, encouraging communities to identify their particular needs and the resources that would best meet those needs.

Critics may caution that such grants could incentivize overidentification of students impacted by ACEs. ${ }^{313}$ While this raises a legitimate concern, grants would not need to be tied to disability identification, but rather, could be tied to data gathered in universal screening tools. Grants may be awarded to schools who can demonstrate that a certain percentage of their student population has experienced four or more ACEs, regardless of whether or not those students could qualify as "individuals with disabilities." While compelling legislative action will undoubtedly be challenging, there are at least two reasons to suggest this may prove a viable path forward. First, ACEs have emerged as a pressing national issue gaining grassroots momentum in recent years, making it ripe for aggressive lobbying efforts and legislative action. Second,

\footnotetext{
factors, including unusually high rates of poverty, child homelessness, single-parent and nonEnglish-speaking households, incidence of low birthweight and HIV/AIDS infection, and participation in supplemental assistance programs. Id.

313. Daniel J. Losen \& Kevin G. Welner, Disabling Discrimination in Our Public Schools: Comprehensive Legal Challenges to Inappropriate and Inadequate Special Education Services for Minority Children, 36 HARV. C.R.-C.L. L. REV. 407, 412 (2001) (“Although African Americans appear to bear the brunt of over-identification, the evidence indicates that all minority groups are vulnerable to discrimination in identification for special education.").
} 
successful models of competitive grants for targeted educational improvements already exist, marking a clear path forward for similar grants addressing ACEs. ${ }^{314}$

Over the last decade, a concerted grassroots movement to educate schools and parents about ACEs has taken considerable hold. ${ }^{315} \mathrm{~A}$ significant uptick in both state and federal ACEs-related legislation is irrefutable. ${ }^{316}$ Many of these proposed bills, particularly at the federal level, have focused on addressing trauma through health care systems rather than schools. ${ }^{317}$ Notably, Illinois recently passed legislation that would mandate schoolwide social emotional screening as part of every child's regular school enrollment. ${ }^{318}$ As grassroots movements around ACEs continue to grow, advocacy groups can lobby for financial support at local, state, and federal levels that is targeted at remediating the effects of ACEs in schools. While universal screening is an excellent first step, schools will need additional dollars to implement training and offer comprehensive mental health supports to fully address student needs. ${ }^{319}$ In many ways, the groundwork has already been laid for these efforts. ${ }^{320}$

Moreover, several education-based grant programs serve as successful models of funding streams targeted at addressing unmet needs of specific cohorts of students. A successful federal program could be created

$\begin{array}{ccccc}\text { 314. Office of Special Educ. } & \text { Programs, } & \text { DISCRETIONARY } & \text { GRANTS } & \text { DATABASE } \\ \text { https://publicddb.osepideasthatwork.org/ } & \text { [https://perma.cc/74L8-SL4D] } & \text { [hereinafter }\end{array}$ DISCRETIONARY GRANTS DATABASE].

315. Alexandra Maul, State and Federal Support of Trauma-Informed Care: Sustaining the Momentum, CTR. FOR HeAlth CARE STRATEGIES (Sept. 27, 2017), https://www.chcs.org/statefederal-support-trauma-informed-care-sustaining-momentum/ [https://perma.cc/ZH5G-FGFH] (referencing almost forty bills in eighteen states that were submitted to legislatures in 2017). The bills instituted a variety of practices including ACEs screenings, trainings, and interdisciplinary collaboration between healthcare, education, child welfare, and behavioral health providers. Id.

316. Id.; see also Jonathan Purtle \& Michael Lewis, Mapping "Trauma-Informed" Legislative Proposals in U.S. Congress, 44 Admin. \& Pol'y Mental Health Servs. Res. 867, 870 (2017) (finding that forty-nine bills were introduced in U.S. Congress that used trauma-informed language).

317. The Trauma-Informed Care for Children and Families Act of 2017 was introduced in Congress in December 2016 and aims to increase understanding and awareness of trauma and identify best practices for prevention and treatment. S.774, 115th Cong. (1st Sess. 2017-2018).

318. Ill. S.B. 565, 99th Gen. Assemb. (Ill. 2017).

319. EKLUND \& ROSSEN, supra note 166, at 8-9 (discussing the benefits of implementing universal screenings as an essential component of multi-tiered systems of support).

320. Massachusetts enacted a state law that provides grant funding to develop trauma-sensitive schools. Initially, the law provided grants to schools interested in developing the infrastructure for teacher training, counseling and other classroom accommodations to support the "psycho-social needs of children whose behavior interferes with learning, particularly those who are suffering from the traumatic effects of exposure to violence.” MASS. GEN. LAWS ch. 69 § 1N (2016). A second law was passed to impose standards on trauma identification and appropriate accommodations. Id., ch. 69 $\S 1 \mathrm{P}$. 
through discretionary grants, a competitive application process administered through the Department of Education, or through set- aside funding provided through the IDEA. The U.S. Department of Education already facilitates the distribution of several targeted discretionary grants, including funds targeted at training for bilingual teachers, implementation of schoolwide positive behavioral interventions and supports, and developing effective partnerships between schools and mental health systems. ${ }^{321}$ The Office of Special Education Programs also facilitates discretionary grants to meet discrete needs within the special education community and funds programs specific to the development of traumainformed practices. ${ }^{322}$ Another funding stream could be dedicated through the use of a portion of money already allocated to states through the IDEA. This would require amending the IDEA, but such amendments have been successful in the past. In 2004, Congress amended the IDEA to include a provision for the permissive use of funds directed at early intervening services. ${ }^{323}$ The point was to target funds and, consequently, services towards students who were struggling academically or behaviorally, but who were not yet identified as eligible students with disabilities. ${ }^{324}$ Similarly, IDEA funds could be directed to benefit students impacted by ACEs who require interventions to address behavioral or academic challenges, but who may not be eligible as students with disabilities under the law.

The focus on creating funding streams for grant-based programs to address the impacts of ACEs is not without its challenges. It will require effective lobbying and advocacy to convince legislators to direct funding to this cause. Even if passed, school leaders would have to apply for such funding. Many school leaders and districts are already overwhelmed with the number of grant and IDEA reporting requirements that are necessary for existing school programs. However, if research around ACEs is correct, the problem is widespread and touches many communities at a fundamental level. For some communities, school-based supports may be the most effective tool to improve not only academic outcomes, but also ensure a greater chance of long-term success outside of the classroom. As the evidence-based practices to help stem the tide of ACEs become more

321. Forecast of Funding Opportunities Under the Department of Education Discretionary Grant Programs for Fiscal Year (FY) 2018, U.S. DEP'T EDUC., https://www2.ed.gov/fund/grant/find/edliteforecast.html [https://perma.cc/3JMK-H9M6].

322. DiSCRETIONARY GRANTS DATABASE, supra note 314.

323. 20 U.S.C. $\S 1413$ (f) (2012); 34 C.F.R. $§ 300.226$ (2019) (permitting school districts to use up to $15 \%$ of funds it receives through IDEA's Part B formula grant to provide early intervening services to children who are struggling academically or behaviorally but are as yet, unidentified).

324. 71 Fed. Reg. 46,540, 46,626-28 (Aug. 14, 2006) (to be codified at 34 C.F.R. pts. 300-301). 
effective and prominent, the desire to implement them should only increase. ${ }^{325}$ If so, the resources - not the resolution - to implement them will be most crucial.

\section{CONCLUSION}

Children living in communities plagued by drug epidemics, marred by violence, and devoid of economic development are, undoubtedly, affected by their environments. Quite clearly, these children face an uphill battle for educational success and have largely been left to fight it alone. Advocates should be commended for shining a light on these inequities and for their attempt to bring immediate remedies to ACEs-impacted students. The breadth of this problem requires both immediate and largescale solutions. But distorting disability rights laws in an effort to create systemic remedies is both unfeasible and potentially harmful.

An effective solution demands a more nuanced legal strategy and the tenacity to engage lawmakers. Advocates should harness the power of individual students' viable claims to pressure schools for universal ACEs screenings. Screenings will sort children impacted by ACEs from those who are not and serve as the gatekeeper to the services that students with disabilities so desperately need. With actual knowledge of disabilities, schools are obligated to target services at individualized needs. And if aggregate data revealed the need for schoolwide interventions, schools could go one step further and implement them.

Given the scope of need in these schools and the limited resources they have to meet them, existing law alone may not be enough to secure effective remedies. Advocates must also channel the grassroots momentum around ACEs awareness to lobby state and federal legislatures for targeted funds. These funds could be used to implement school-wide programs that do not involve disability determinations, thus averting the potential for over identification of students as disabled. Legislative reform is never easy, but the science evidencing the impacts of ACEs is undeniable. Schools and lawmakers either leave students to confront these weighty challenges on their own, or they can act now to provide students with supports that make a meaningful difference.

325. Ctr. on the Developing Child at Harvard Univ., From Best Practices to BREAKTHROUGH IMPACTS 19 (2016), https://46y5eh11fhgw3ve3ytpwxt9r-wpengine.netdnassl.com/wp-content/uploads/2016/05/From_Best_Practices_to_Breakthrough_Impacts-4.pdf [https://perma.cc/AR9L-KSP8]. 